\title{
Characteristics and scenarios of solar energy development in Iran: Fuzzy cognitive map-based approach
}

\author{
Mahdi Alipour $^{\text {a }}$, R. Hafezi ${ }^{\text {b, }}$, E. Papageorgiou ${ }^{\text {c }}$, M. Hafezi ${ }^{\text {d,e }}$, M. Alipour ${ }^{\text {de, }, *}$ \\ ${ }^{\mathrm{a}}$ Faculty of Mechanical Engineering, Amirkabir University of Technology, 424 Hafez Ave., P.O. Box 15875-4413, \\ Tehran, Iran. \\ ${ }^{\mathrm{b}}$ Futures Studies Research Group, National Research Institute for Science Policy, Tehran, Iran. \\ ${ }^{\mathrm{c}}$ Faculty of Technology, University of Thessaly, Larisa 41110, Greece. \\ ${ }^{\mathrm{d}}$ Griffith School of Engineering and Built Environment, Griffith University, Southport, QLD, 4222, Australia. \\ ${ }^{\text {e } C i t i e s ~ R e s e a r c h ~ I n s t i t u t e, ~ G r i f f i t h ~ U n i v e r s i t y, ~ N a t h a n, ~ Q L D ~ 4111, ~ A u s t r a l i a . ~}$
}

\begin{abstract}
Widespread use of promising solar energy is an integral attribute of governments toward global efforts in mitigating future emission and reducing the fossil fuel consumption trajectory. However, the outlook of solar energy development at the strategic level is driven by inherent uncertainties in a long-term perspective. As these unpredictable volatilities come into play, they heavily influence the future trends formed by a range of exogenous and endogenous factors including Political, Economic, Social, Technological, Environmental, and Legal (PESTEL). This study aimed at identifying, characterizing, and analyzing influential PESTEL factors shaping the dynamics of Solar Photovoltaics (SPV) in an uncertain environment. For this purpose, the Fuzzy Cognitive Mapping (FCM) method was employed for the case of Iran to investigate how involved factors dynamically interact and collectively behave in the system. A participatory stepwise framework was developed consisting of three steps by conducting a survey and two workshops with the participation of multidisciplinary stakeholders. Aa a result, a semi-quantitative model was formed in an integrated FCM comprising 31interwoven concepts. To further outline possible future trends, five key concepts were determined that explored four plausible projections of Iran's SPV sector. The scenario outcome suggests that the industry is profoundly affected by external economic and political factors. Two scenarios "Cornered in a Dead-End" and “At Wits' End” project that, by 2030, the sector experiences a declining growth trend. "The Period of Tolerance” scenario does not envisage a dramatic change from the current trajectory, while in only "Blue Sky" the country's SPV sector anticipate a moderate growth.
\end{abstract}

Keywords: Solar energy; Uncertainties; Characteristics; Scenario Planning; Fuzzy Cognitive Mapping (FCM); Renewable energy.

\footnotetext{
* Corresponding authors. Futures Studies Research Group, National Research Institute for Science Policy (NRISP), No. 9, Soheil St., South Shirazi St., Mollasadra Ave., Vanak Sq., Tehran, Iran. E-mail address: r.hafezi@aut.ac.ir (R. Hafezi).

Griffith School of Engineering and Built Environment, Gold Coast Campus, Griffith University, Parklands Drive, Southport, QLD 4222, Australia. E-mail address: Mohammad.Alipour@Griffithuni.edu.au (M. Alipour).
} 


\section{Introduction}

The roller-coaster of Iran's foreign policy is rolling fast fueled by nuclear issues with strong participation of world powers. The latest saga has emerged as economic and trade sanctions on November 2018, this time imposed by the U.S.

The resulting variations in political shifts have been dramatically apparent on the country's energy sector over the past years. Privatization and economic reform have been stalled at the expense of these disruptions, such that the reliance on oil and gas exports has remained at $60 \%$ of total revenues and $80 \%$ of export revenues [1]. Abundant sources of renewable energies (REs) relying financially on fossil fuel exports have been one of the more vulnerable yet less prioritized sectors [2]. At the center of this exposure is solar energy where the industry is facing an uncertain future on both residential and utility-scale sectors. Uncapped solar energy has been one of the alternative resources that was hoped to ease the burden on fossil fuel power plants in Iran's 20year vision. The 5,184 TWh/year of radiation holds promise for the high potential of solar photovoltaic (SPV) in Iran as the seventeenth country in radiation received [3] (Fig. 1). The sector enjoyed a promising spell of development during 2015-2017 but the ascending trend did not last long (Fig. 2). Nevertheless, while this rapid growth came from direct governmental investment on SPV power stations, the adoption level at the residential sector has largely remained stagnant [4].

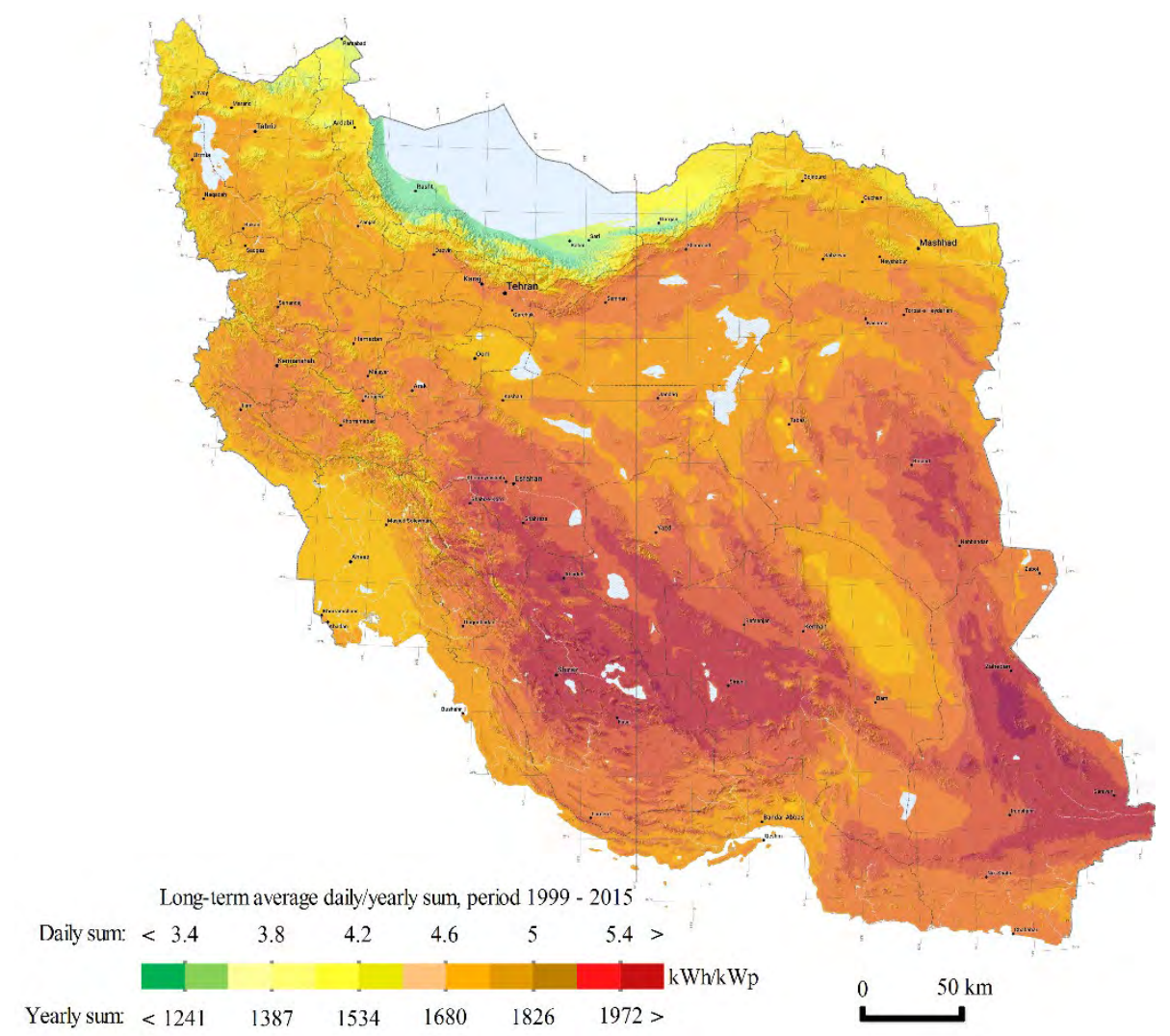

Fig. 1. The potential of SPV power generation in Iran [5]. 


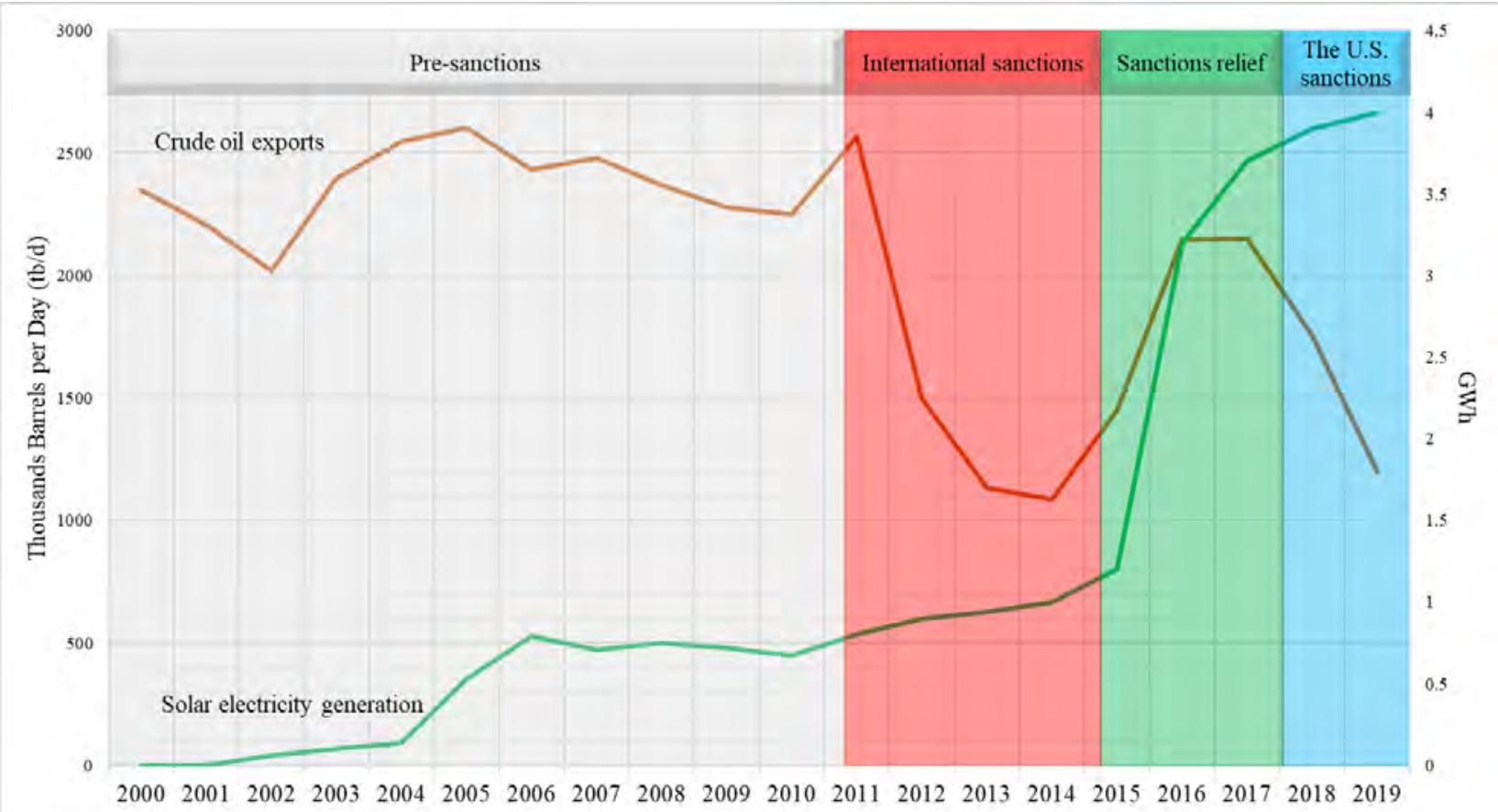

Fig. 2. Oil export and solar electricity production over the past years under different political conditions $[6,7]$. Two waves of sanctions targeting the energy sector have concentrated on oil exports as the primary source of government revenue. The first wave (from 2011 to 2015) imposed by UN, the U.S., and European Union was lifted by the nuclear agreement in July 2015; the second wave recently started in 2018 is being led by only the U.S.

The current general trend of SPV installations presents no clear scheme for the future nor promises sustainable growth. Propositions of SPV development is rather characterized by external unstable factors that contribute to contradictory perspectives, rendering the country's solar sector largely vulnerable and overly exposed against these externalities. This research epitomizes the impact of these factors that facilitate the attainment of a more interactive and tangible interpretation of the future of the SPV industry. The emphasis is on generalized and macro factors rather than individual predictors of households' adoption behavior since: (1) policy decisions on investment, regulations, and incentives (e.g., grants, feed-in tariff (FiT), rebates, and other supporting packages) are extrinsic; (2) the level of knowledge and awareness in the residential sector is low due to the marginal impact of social influence, peer effects, and mass media; and (3) the current system costs are not affordable and viable for the residential sector (lack of behavioral control), making motivation, attitude, intention, and subsequently, adoption behavior [8] of households less relevant toward the adoption of innovation. These implications manifest the passive influence of homeowner and active role of government in the development and diffusion of Iran's SPV technology at, which entails applying a modeling approach at high level.

Understanding the future of energy modeling systems is unfolded through several mathematical and statistical methods $[9,10]$. Pure mathematical methods are more efficient in a stable condition and for short-term assessments [11]. Examples of the approaches comprise: Artificial neuralnetwork, Autoregressive integrated moving average (ARIMA) models, Bayesian vector 
autoregression, Regression models, Genetic algorithm models, Time series models, and Grey prediction. Energy system models (e.g., LEAP, MESAP, EFOM, MARKAL, TIMES, RESGEN, NEMS, POLES, WEM, SAGE, PRIMES, MESSAGE) ${ }^{1}$ conduct long-term evaluations when the extensive data from several sectors are available. In these approaches, the geographical of some methods are limited to local, computing requirement is high, and some are specified for a specific area (e.g., WEM). The focus of these methods is principally on final prediction outcome using a set of quantified parameters while their causality and evolvements are not under attention. Simulation modeling techniques address feedback dynamics of the system and have been well studied in the energy domain [12-15]. However, these methods require rigorous computational knowledge with an extensive level of data. Agent-based models and Discrete Event are preferred for the micro level of modeling. Agent-based models are particularly useful for exploring households' behavior (of solar adoption) who are intelligent and interact with each other [16-18]. System dynamics approach fits well for the macro-level [19, 20], but then again contains arguably too mathematical details to be used for experts. The applicability of Integrated Assessment Models (IAMs) are of also extensive interest in incorporating a broader set of climate and environmental change disciplines [21].

A useful semi-quantitative method capable of modeling at the strategic level is Fuzzy Cognitive Map (FCM). FCM can be effectively applied to deal with a complex problem in an uncertain environment where the relations of less detailed concepts are holistic and non-linear. FCM is quite simple to use, adaptable for policy analysis at the higher level, can incorporate macro dimensions, and does not require rigorous empirical data [22]. The simple nature of the method is conveniently friendly-user for policymakers, yet powerful for zooming out to capture high abstraction of the complex problem. While its simulation outcome is useful for realization and insight of the system, it provides an adequate future trend(s) through the diversity of perspectives of mental models. When coupled with descriptive tools, it becomes an effective approach capable of dealing with vast domains of inherent uncertainties [23]. Future study has witnessed a spurt in the use of FCM in a wide range of sciences, including energy [24, 25], management [26, 27], climate changes [28, 29], environmental and ecosystem [30-35], regional planning [36], medical and medicine [37-39], engineering [40-42], and social studies [43, 44]. This study applies FCM empowered with realworld narratives to scrutinize the characteristics, interactions, and influence of factors on Iran's SPV sector, and elicit plausible scenarios based on the dynamic behaviors of these influential factors and uncertainties surrounding the sector.

Recent sweeping changes leading to ambiguity call for focus on alternative futures. This entails highlighting the latest uncertainties and volatilities that have eclipsed the country's energy structures. Granted alternative futures of energy sector have been well covered, the two or at least one of the recent waves of international shifts (Fig. 2) are overlooked in all researches [45-49]. This is while investigations on solar futures are rather scarce. Thus, with focus on the SPV sector at strategic level, the latest political shifts are embedded in this work aimed at updated robust decisions and proper policymaking. The research proceeds as follows: Section 2 briefly describes

\footnotetext{
${ }^{1}$ LEAP: Long-range Energy Alternatives Planning System; MESAP: Modular Energy System Analysis and Planning Environment; EFOM: Energy Flow Optimization Model; MARKAL: MARKet Allocation model; TIMES: The Integrated MARKAL-EFOM System; RESGEN: Regional Energy Scenario GENerator (RESGEN) model; NEMS: National Energy Modeling System; POLES: Prospective Outlook on Long-term Energy Systems; WEM: World Energy Model; SAGE: System for the Analysis of Global Energy markets; PRIMES: Price-Induced Market Equilibrium System; MESSAGE: Model for Energy Supply Strategy Alternatives and their General Environmental Impact.
} 
FCM, the development process of the model, determination of key concepts, and storylines of scenarios. Characteristics of concepts and simulation results of the developed FCM are provided in section 3 . The last section is devoted to the discussions and concluding remarks.

\section{Method}

\subsection{Fuzzy Cognitive map}

Cognitive mapping was first introduced by Axelrod in 1970s to represent socio-political knowledge [50]. Popular for capturing the causal knowledge and mental models, cognitive maps comprised nodes (variable concepts) and edges (causal connections) in between them. To indicate the type of the causal relationship between two concepts, connections were assigned positive or negative directions but with equal impact (i.e., accepting one of 1,0 or -1 numbers) [51]. A positive link between two nodes (A to B) indicates that A causally increases B, whereas a negative link from A to B means A causes the reduction of B. Regarded as rigid and too binding in nature, FCM was introduced as the extension of cognitive mapping to address vagueness and degree of influence of the concepts [52]. Links between the nodes are assigned weights to quantify the strength of their causal relationships. The fuzzy logic added to cognitive maps manifests the degree of ambiguity involved in human reasoning. In the FCM, concepts not only take 1, 0, or -1, but all other real numbers in $[-1,1]$. The addition of fuzzy numbers enables highlighting the level of influence and impact that concepts have on other concepts and also on the system, resulting in a higher accuracy of the analysis. An example of the structure and the difference between the simple and fuzzy causal cognitive map is illustrated in Fig. 3. As is shown, the topology of these models is similar to feedback nonlinear neural network.
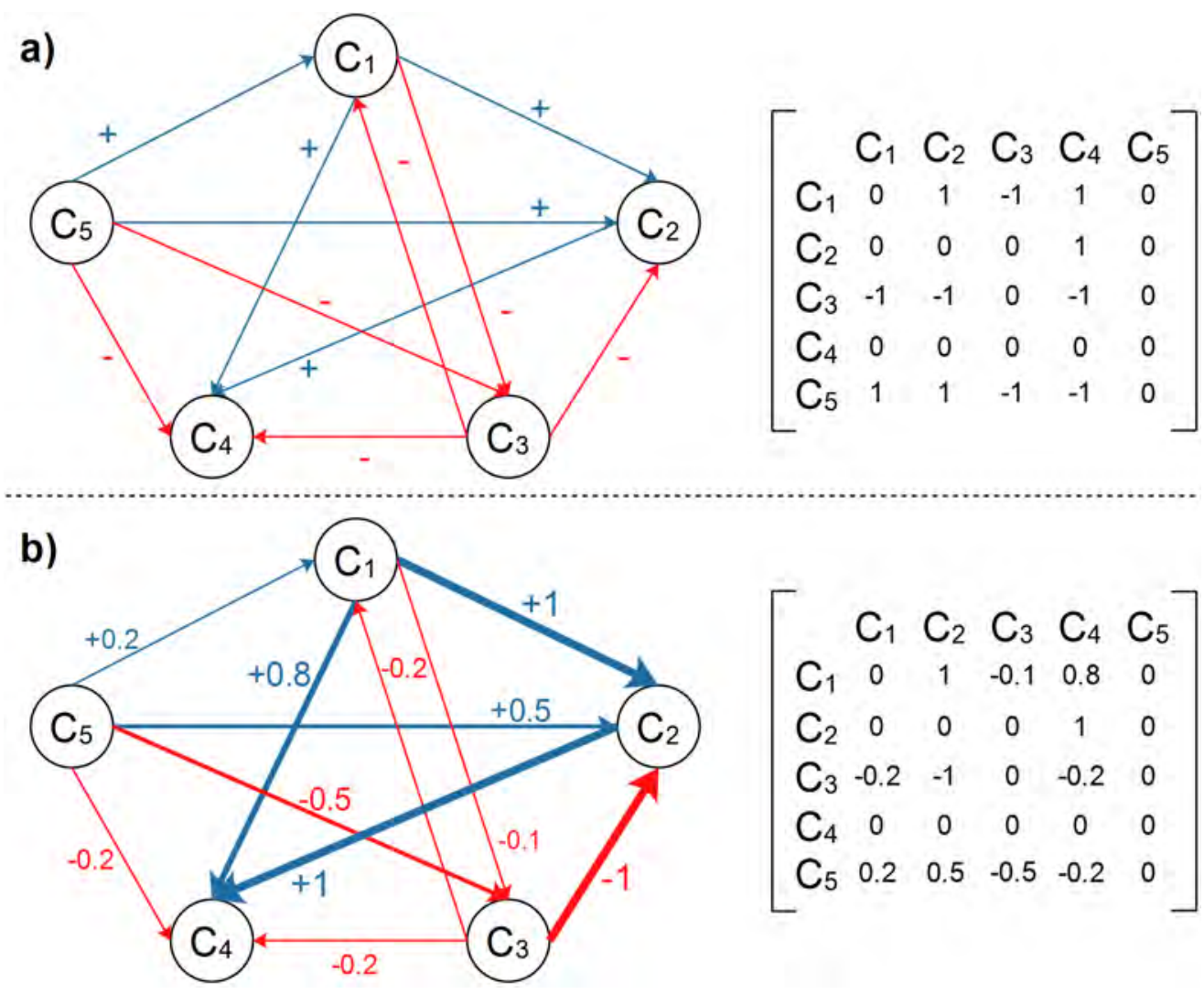
Fig. 3. (a) A cognitive map, and (b) a fuzzy cognitive map, with their correspondent weight adjacency matrix (right), showing the positive and negative causal influences.

In an FCM, concepts take the fuzzy values in the range between $[0,1]$ (or $[-1,1][53]$ ) and weights of the arcs/interconnections belong to the interval [-1,1] [33]. This provides hazy degrees of causality between hazy casual concepts. There are three different types of possible causalities $\left(R_{i j}\right)$ between every pair of concepts $\mathrm{Ci}$ and $\mathrm{Cj}$ :

$R_{i j}>0$ : positive causality, where $C_{i}$ casually increases $C_{j}$,

$R_{i j}<0$ : negative causality, where $C_{i}$ casually decreases $C_{j}$, and

$R_{i j}=0$ : no causality between $C_{i}$ and $C_{j}$.

An example of an FCM with its corresponding adjacency weight matrix is illustrated in Fig. 3. The overall causal effect in FCM is defined by the sum of all direct and indirect effects through various available paths [50]. For example, in a path comprising of a series of causal relations, the cumulative effect is positive if the path includes an even number of negative links, negative otherwise. If all indirect causal paths lead to positive effect, the overall causal effect of an FCM is positive, and similarly, the overall causal effect is negative if all indirect paths represent negative effects. When the FCM network contains both positive and negative effects, indeterminacy prevails (see Fig. 4)
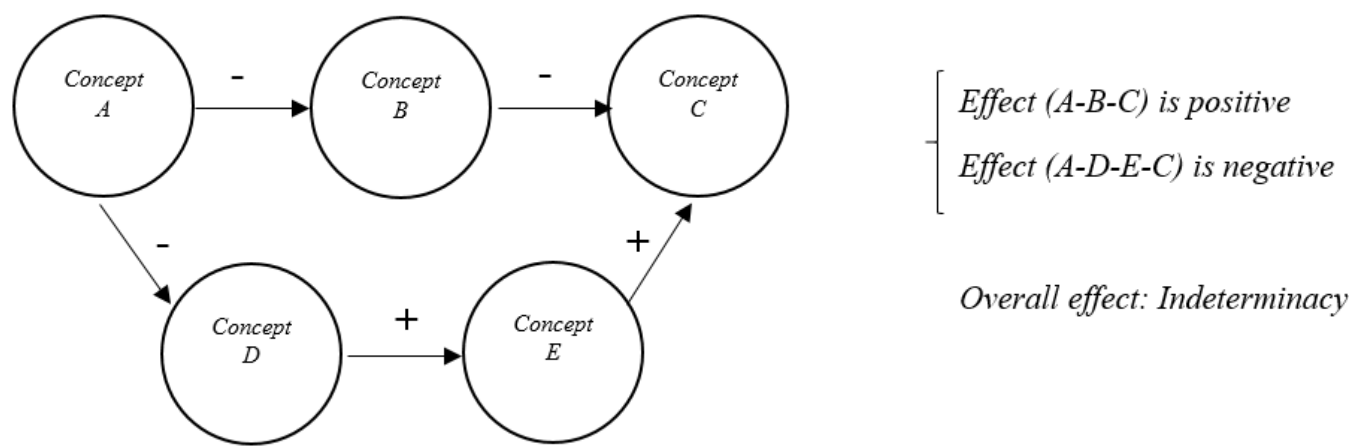

Fig. 4. An example of a given cognitive map with indeterminacy.

As noted, the logic of an FCM developed upon feedbacks refer to forward iterations. A mathematical formulation is allocated to calculate values of the corresponding variables for each concept. Typically, an FCM of $n$ concepts could be represented mathematically by a $n$ state vector $(A)$ which gathers the values of the concepts and by a $n \times n$ weight matrix $(W)$. Having assigned values $A_{i}$ to the concepts $C_{i}$ and weight among concepts, the FCM converges to an equilibrium point using one of the below calculation rules, Eq. (1)-(3) [54]:

Kosko:

$$
A_{i}^{(\kappa+1)}=f\left(\sum_{j=1, j \neq i}^{n} w_{j i} \times A_{j}^{\kappa}\right)
$$


Rescale:

$$
A_{i}^{(\kappa+1)}=f\left(\left(2 \times A_{i}^{\kappa}-1\right)+\sum_{j=1, j \neq i}^{n} w_{j i} \times\left(2 \times A_{j}^{\kappa}-1\right)\right)
$$

where $A_{i}^{(\kappa+1)}$ is the value of concept $C_{i}$ at simulation step $\kappa+1, A_{j}^{(\kappa)}$ is the value of concept $C_{j}$ at the simulation step $\kappa, w_{i j}$ is the weight of the interconnection between concept $C_{i}$ and concept $C_{j}, \kappa$ (Greek letter Kappa) is the interaction index an every simulation step and $f(\cdot)$ is the threshold (activation) function. The function is selected to retain the values within the range $[0,1]$ or $[-1,1]$. The modified Kosko (Eq. (2)) is the original Kosko activation function (Eq. (1)) that takes past values (or history) of a concept into account [55]. Generally, there are four most commonly used transformation functions Eq. (4)-(7): (a) bivalent, (b) trivalent, (c) sigmoid and (d) hyperbolic tangent.

Bivalent: $\quad f(x)= \begin{cases}1, & x>0 \\ 0, & x \leq 0\end{cases}$

$$
\begin{aligned}
& \text { Sigmoid } \\
& \text { (linear): }
\end{aligned}
$$

Trivalent: $\quad f(x)= \begin{cases}1, & x>0 \\ 0, & x=0 \\ -1 & x<0\end{cases}$

$$
\begin{aligned}
& \text { Hyperbolic } f(x)=\tanh (\lambda \times x) \\
& \text { tangent: }
\end{aligned}
$$

where $\lambda$ is a real positive number $(\lambda>0)$ which determines the steepness of the continuous function $f$ and $x$ is the value $A_{i}^{(\kappa)}$ on the equilibrium point. At each step, the value $A_{i}$ of a concept is influenced by the values of concepts connected to it and it is updated according to the inference rule. This process continues until the system converges which indicates that the difference between two subsequent value of the outputs values must be equal or lower to $\varepsilon$ (epsilon, $\varepsilon=0.001$ ). In most studies, the sigmoid function is applied widely to obtain the inference of the system [56], which highlights the extent or the degree of the output. Unlike simple binary function where the values of concepts are either 1 (turned on) or 0 (turned off), sigmoid squashing function reveals any other concepts that stand between 1 and 0 indicating as "slightly on" and "slightly off" [57]. Broadly, the nodal values of $0<x \leq 1$ represent a positive influence, $-1 \leq \mathrm{x}<0$ denote a negative influence or decreasing in beliefs, and 0 denotes no effect. This wider range of more accurate results helps to interpret the map with more in-depth knowledge.

The mechanism of FCM allows the model to express forward and backward propagation of causality dynamically over time, through which, casual effects may change input values to express fluctuations. As a result, FCMs provide nonlinear feedbacks since they can only be modeled under a time-based system structure. FCMs are employed to model causality to explore the implications of complex conceptual models with closed loops, not merely semantic relationships between 
concepts [58]. FCMs, in a matrix or graphical format, can be applied using expert-based or computational methods. The first approach is developed manually by experts [59], and the second uses an automated learning method to manipulate the data [60]. To explore their benefits and limitations in developing scenarios for Iranian SPV sector, we use the expert-based method because it does not need secondary data and information.

\subsection{Developing FCM}

The FCM development process was conducted in three steps (Fig. 5). The first step involved concepts identification through a literature review and a survey. An initial list of concepts potentially influential on the country's solar sector was elicited from the literature review. The term solar energy in this study refers to on/off-grid SPV at both residential and utility-scale segments. The identified concepts were classified into six main categories: Political, economic, social, technological, environmental, and legal (PESTEL); and then used in a survey to evaluate their relevance. This classification was purposely designed to (a) facilitate survey respondents to find any missing concept, (b) promote weights assignment by experts, and (c) derive some interesting generalized outcome from the developed FCM (described in section 3.1). Sixty-five postgraduate students in the field of energy engineering and foresight from three Tehran universities were invited through email to participate in this short questionnaire (provided in Supplementary Data). The respondents were asked to rate the relevance of fifty-seven concepts using a 7-point bipolar Likert scale as an answering instrument with "totally irrelevant" coded as 1 to "totally relevant" coded as seven on all concepts. New concepts (and its rate of relevance) could also be added by the respondent at the end of each main category if there was any (Fig. 5).

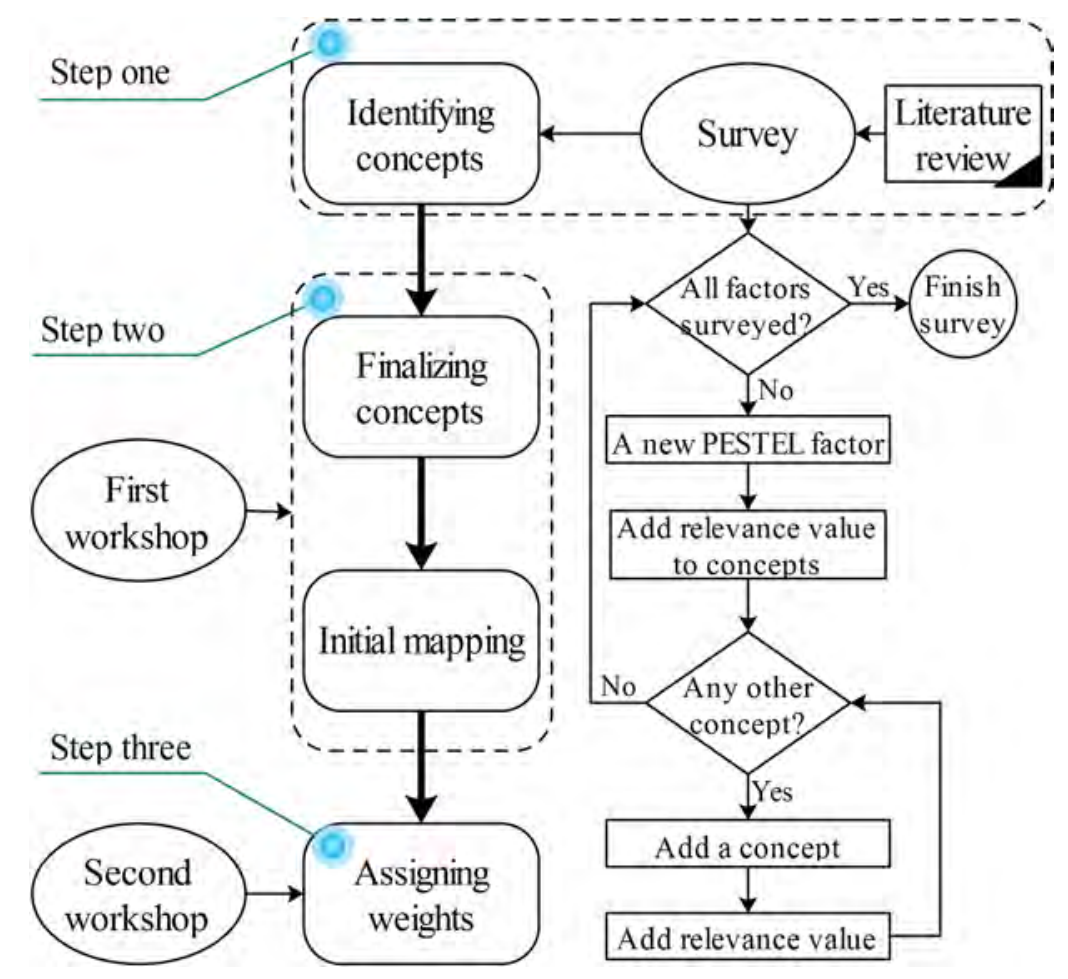


Fig. 5. Three steps of the FCM development process. The flowchart of the survey described on the right side was performed for concepts classified in economic, political, social, technological, environmental, and legal categories (PESTEL).

The total response rate after three weeks was 38.2\% (21 responses). Responses were aggregated for each concept, concepts rated "somewhat relevant" or above were handed to the experts in step two. In this step, a workshop was held to identify interactions between concepts and form the cognitive map. To this end, ten experts from five different academic institutions and four participants from Renewable Energy and Energy Efficiency Organization (SATBA) representing different disciplinary backgrounds formed the expert group. The selected concepts (from the first step) were first modified, filtered, merged, or broken down by the attendees for finalization which handed a total of 31 (65.2\% of initial concepts). At the end of the workshop, causal links and positive/negative interactions between concepts were discussed to map the initial model representing the consensus opinion of all participants.

The last step of the FCM development process constituted another workshop with the same experts to assign weights to each link. The printed graphical model resulting from the first workshop output was used in the second workshop to visually facilitate the assessment. To smooth the process and adequately capture strength (weight) of the causal links, main factors (PESTEL) (and their respected concepts) were divided into two segments (1- economic, 2- other factors) with an equal number of concepts. Experts were also divided into two subgroups of seven, and each was assigned a segment based on their expertise. Since Hyperbolic tangent function (tanhx) is a recommended squashing function for its strength in highlighting extend or degree of interactions [61], experts were opted for weighting the causal links in the interval $[-1,+1]$. Sharing the assigned weights consensus within subgroup members with the other subgroup warranted a thorough understanding of the system under study. The perceived cognitive map and assigned weights were reviewed and validated at the end of the workshop, with further discussions on developing plausible scenarios. The finalized FCM is illustrated in Fig. 6 representing 31 concepts and 135 connections. 


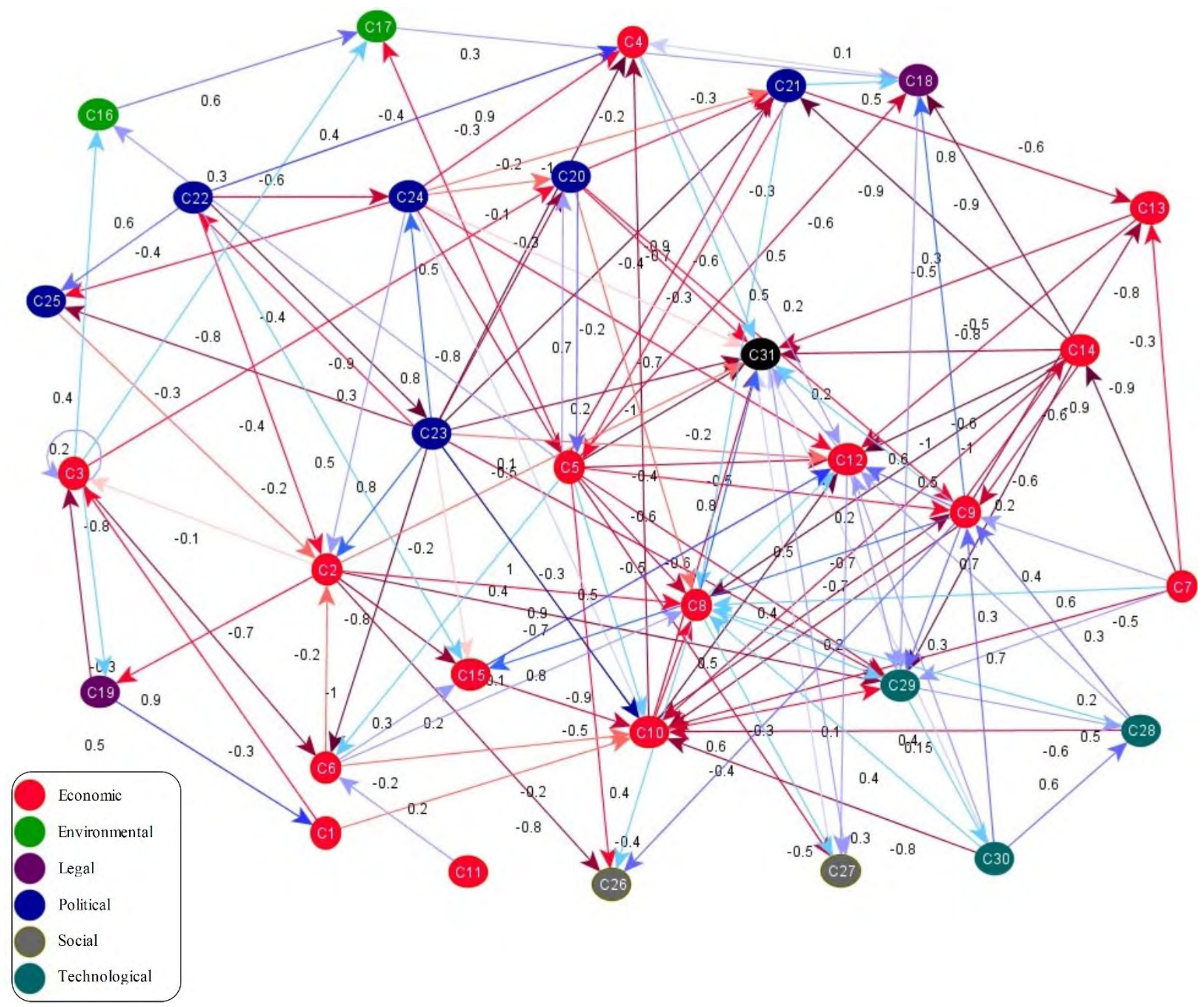

Fig. 6. The finalized FCM visualized by Visone [62].

\subsection{Simulation process}

Simulating the FCM model helps a deeper understanding of the concept's behavior, their relations, and the extent to which one concept has an impact on others. The literature offers a range of tools to design and develop the FCMs, such as Mental Modeler [63], FCMapper [64], ESQAPE [65], FCM Expert [66], FCM-Analyst [67], JFCM [68], and FCM Designer [69], each having different capabilities and specifications. This study employs FCMWizard tool to simulate and analyze the problem (available at http://fcmwizard.com) [70]. 


\subsubsection{FCMWizard overview}

In this section, an overview of the FCMWizard is presented by illustrating the main functionalities and capabilities of the tool. Screenshots of the main menu of the FCM Wizard are presented in Fig. 7. The tool offers three main modes for FCM construction, namely: (i) Expert Mode wherein experts and/or stakeholders can construct manually an FCM for a real problem, (ii) Data-Based (Learning) Mode wherein the model is constructed automatically using given data, and (iii) Merge Mode, where different individual maps can be combined to provide an augmented collective FCM model.

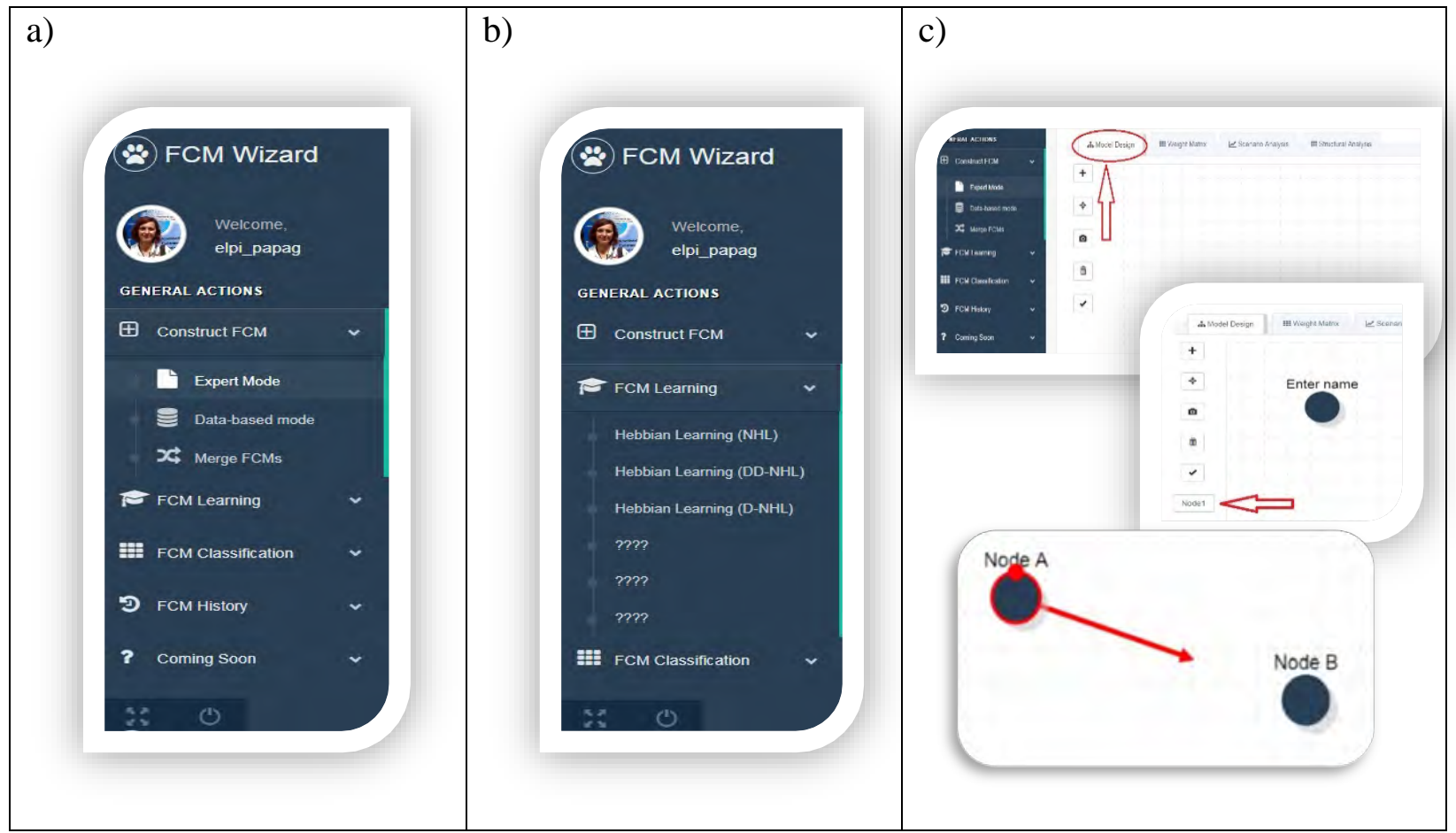

Fig. 7. Main menu of FCMWizard: (a) Construct Mode, (b) Learning Mode, (c) Model Design.

FCMWizard offers the FCM Learning Mode in three modes: (i) Hebbian Learning (NHL): weights are fine-tuned by data assuming that all the concepts are synchronously triggered at each iteration and they synchronously change their values. Constraints on concepts and weights can be considered for updating weighted connections. (ii) Data-driven Hebbian Learning (DD-NHL): an extended NHL method through historical data for the input concepts to fine-tune weights, and (iii) Differential Hebbian Learning (D-NHL): This algorithm correlates the changes in the concepts to modify their weights. It was the first Hebbian learning algorithm proposed by Dickerson and [37].

The first functionality of the tool is devoted to FCM construction without a thorough knowledge of the mathematical foundations of the methodology. Any users can design new a new map independently from the type of the application by adding new concepts and causal relationships between them, using influence weights (see Fig. 7c). For example, selecting the "Expert Mode" under the main menu "Construct FCM", an FCM model can be easily designed. New nodes can be added by selecting the "+” button in the "Model Design” tab. New edges (causal relationships) can be added between nodes. The overall graph map depicts the causal relationships between 
concepts where a direct relationship is shown as a positive weight (green color), and an inverse relationship is shown as a negative weight (red color).

For group modeling, different individuals' cognitive maps can be combined in an easy and meaningful way to produce a collective map, which in general might help to reach consensus, promote learning and reduce conflicts [71]. FCMWizard aggregates different maps by selecting "Merge FCMs" mode. The adjacency matrices are augmented to reflect all proposed concepts from different participants, and then averaging is used to produce the group map.

As FCMs perform like recurrent neural networks, selecting the appropriate transfer function and inference rule (in section 2.1) is a key factor when designing the model (Fig. 8). The tool provides a second category of functionalities that is meant for users with more expertise like FCM analysts who are familiar with the method's mechanics. It involves customizing the inference rules, as presented (Eq. 1-3), the transfer functions (Eq. 4-7), and the different parameters that might influence the convergence of the system into a stable state like the Lambda parameter, the number of iterations and the minimum residual error. This category can be somewhat challenging to other types of users like stakeholders or policy analysts and will necessitate a learning curve. These aspects will impact the model's capability of producing meaningful and accurate results.

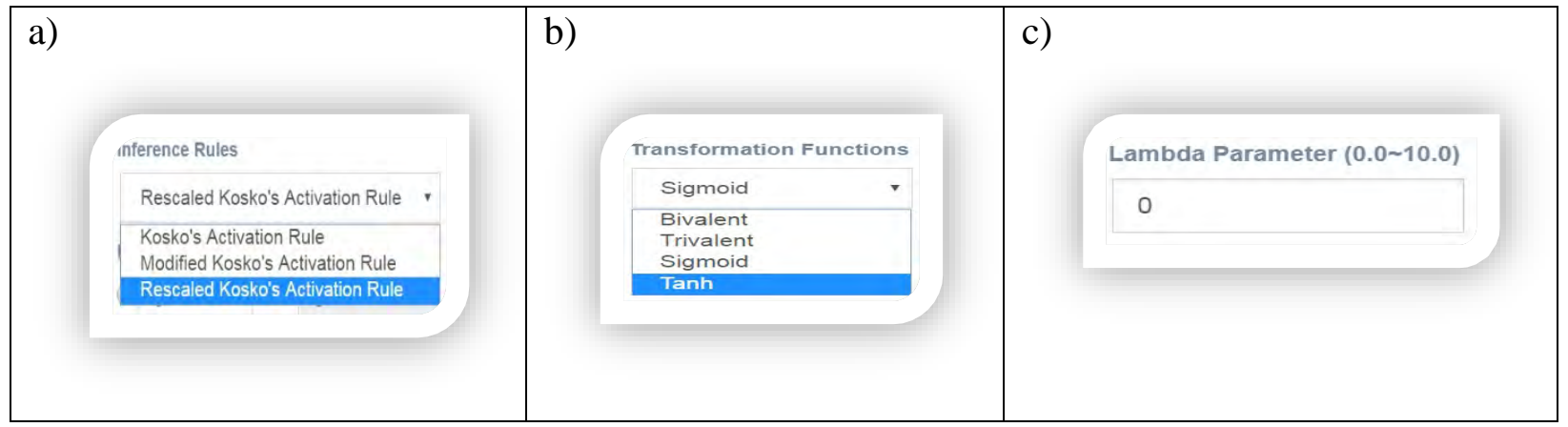

Fig. 8. Selection of (a) Inference Rule, (b) Transformation function and (c) lambda parameter of the transformation function.

The statistical package computes graph theory indices like total number of concepts, number of connections, connection to concept ratio, outdegree, indegree, number of transmitter variables, the number of receiver variables, the number of ordinary variables, complexity ratio, and the hierarchy index (see Fig. 9). FCMWizard can perform a "what-if” scenario analysis by introducing:

- the initial stimulus state vector,

- the inference rule's type,

- the transfer function,

- its learning parameter,and

- the number of iterations or the convergence step. 


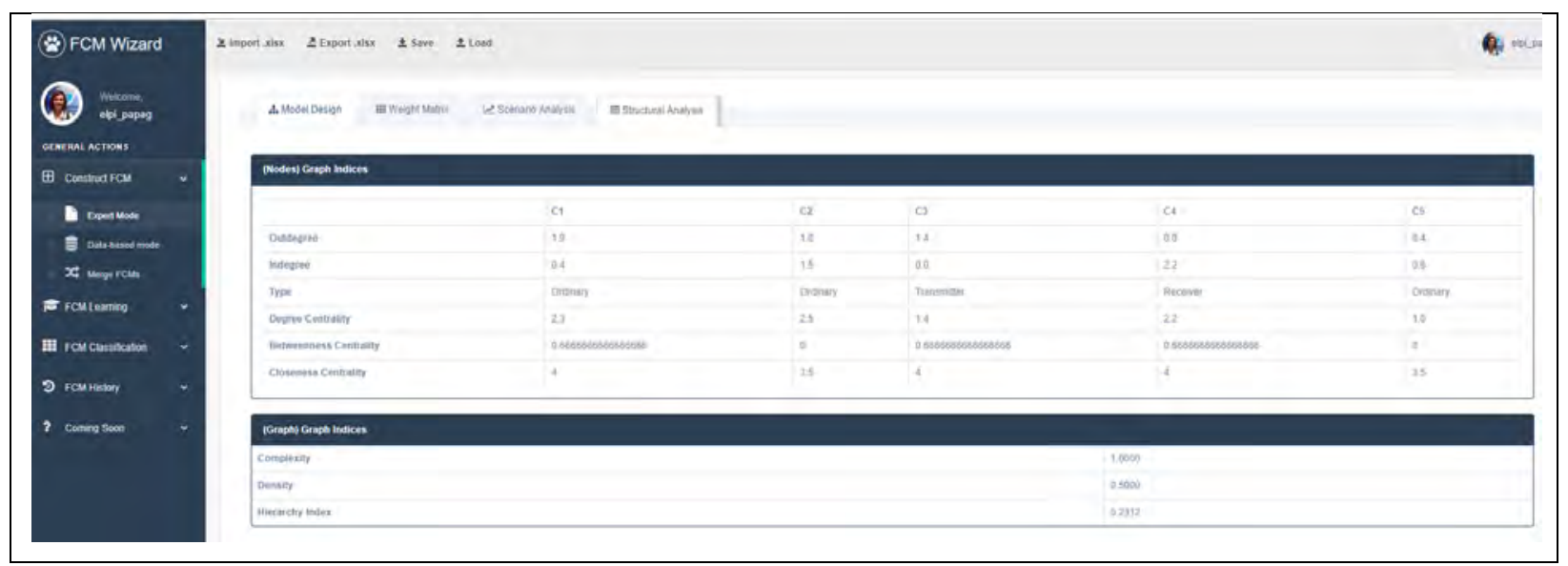

Fig. 9. Screenshot of the "Structural Analysis” tab.

Within the tool, concept values can be clamped, i.e., the value of concepts remains unchanged through the iterations. One brief numerical example of the iteration to perform a scenario analysis for a benchmark ecological problem (see Fig. 10), described in [72], is illustrated below to show the performance of the numerical solution implemented in FCMWizard.

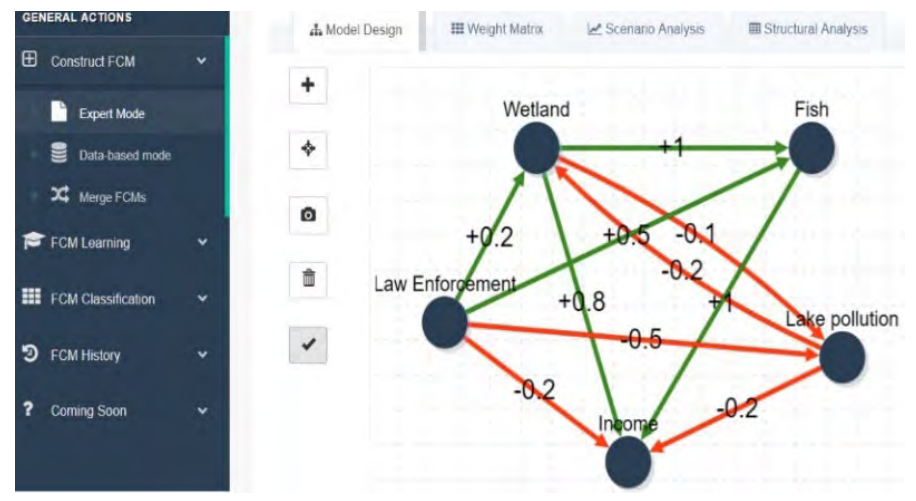

Fig. 10. FCM of ecological model visualized by FCM Wizard.

Following the five steps introduced above for performing scenario analysis, the initial values of the respected five FCM concepts are given (as shown in Fig. 11). The user also selects the modified Kosko rule in Eq. (2), the sigmoid function in Eq. (6), setting the Lambda to one and the convergence step to 0.001, as described in section 2.1. Next, the simulation process takes place based on numerical calculations in Eq. (2) and Eq. (6) and after eight iterations, the model converges in a steady state as depicted in Fig. 12. 


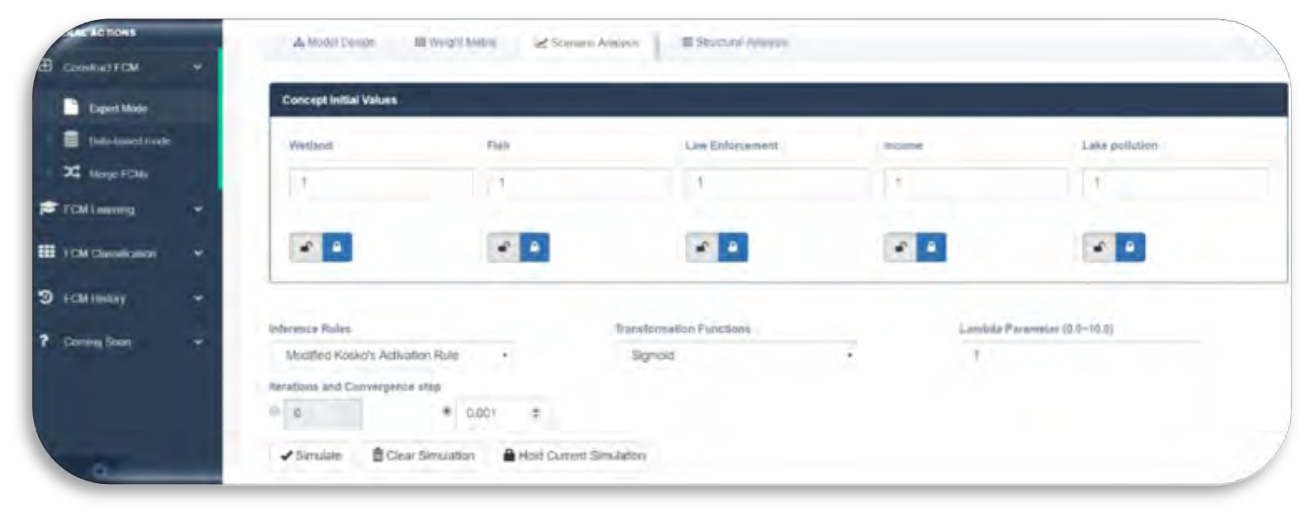

Fig. 11. Screenshot of the "scenario analysis" mode.

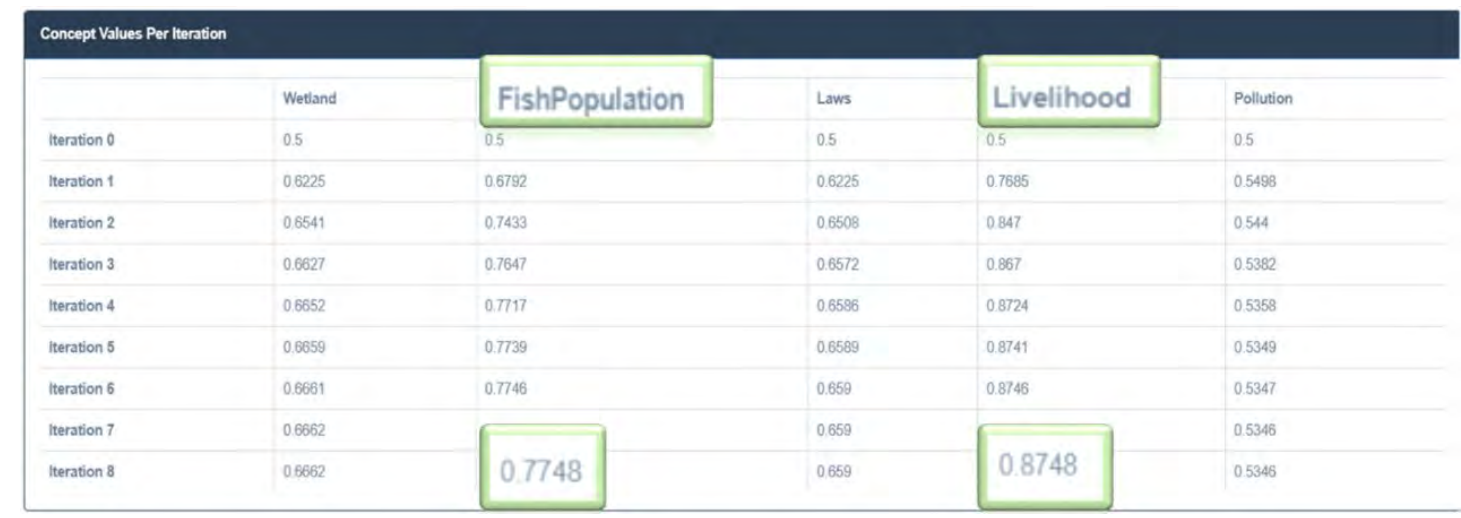

Fig. 12. Screenshot of the FCM iteration steps until model convergence in a steady state.

In this study, FCMWizard parameterizes and converts concepts, causal interconnections between concepts, and the initial values of key concepts into the simulation model resulting in two types of outcome. The first investigated the sensitivity of critical concepts separately on the system (section 3.3); the second type provided the outcome of scenario analysis. The process was performed by clamping the initial value of key concepts. These two outcomes are compared against a baseline scenario where the system reaches the steady state by setting the initial values of concepts at 1 (in Eq. 1) and no clamping.

\subsection{Key concepts}

Limiting concepts to the most influential and uncertain ones become relevant when the number of concepts is too much to be analyzed one by one, there are some autonomous concepts virtually disengaged from the system, or dependent concepts have a relatively low degree in influence but strong dependence. Filtering key concepts is a traditional approach in scenario planning that helps linking storylines to the quantitative model as well as to concentrate on pivotal concepts that often have strong direct or indirect effects on goal while can significantly change the balance of the whole system [57]. In the FCM-based scenario analysis, recognition of key concepts mainly relies upon experts' perception although some characteristics elicited from the model facilitates the procedure. The connection weights reveal three useful indices for this matter: Indegree (weight of 
inbound links), outdegree (weight of outbound links), and centrality. The first two indicate to what extent a concept is a driver (influential) or receiver (dependent). This is similar to the bidimensional categorization of influence-dependence axes in Cross Impact Analysis [58]. Centrality is the relative importance of a concept within the FCM structure, which is calculated by the sum of the corresponding absolute indegree and outdegree causal weights [71]. These calculated indices along with the concepts identified previously are summarized in Table 1.

"Oil price” and "Declining global equipment prices" are two transmitters having zero indegrees but are not influential either ( $9^{\text {th }}$ and $27^{\text {th }}$ in the out-degree ranking, respectively). "Social effect" as the only concept with zero outdegrees is classified as "receiver" or dependent. The five key concepts selected are as: "fossil fuels-based economy", "government investment", "government support”, "investment risk", and "reinstated sanctions". These perceived highly uncertain concepts by experts were selected as they were among concepts with the six highest centralities having both in/out-degree values and could well influence the dynamic of the system. The FCM simulations clamping the value of these concepts are shown in section 3.3 with details on the attributes and characteristics of concepts in section 3 .

Table 1. Finalized concepts, their description, and type with three major indices (indegree, outdegree, and centrality).

\begin{tabular}{|c|c|c|c|c|c|c|}
\hline $\begin{array}{l}\text { Main } \\
\text { factor }\end{array}$ & Concept & Description & Indegree & Outdegree & Centrality & Type \\
\hline \multirow{15}{*}{ 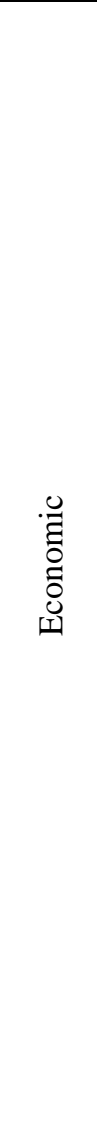 } & $\mathrm{C}_{1}$ : Electricity price & National grid electricity rate for the end-user. & 0.90 & 0.50 & 1.40 & Ordinary \\
\hline & $\mathrm{C}_{2}$ : Economic degradation & $\begin{array}{l}\text { Economic deterioration caused by internal factors and external } \\
\text { pressures. }\end{array}$ & 1.90 & 3.20 & 5.10 & Ordinary \\
\hline & $\mathrm{C}_{3}$ : Energy demand & $\begin{array}{l}\text { From residential and the industrial sector to address domestic and } \\
\text { export demand. }\end{array}$ & 1.40 & 2.50 & 3.90 & Ordinary \\
\hline & $\mathrm{C}_{4}$ : Foreign investment & $\begin{array}{l}\text { Investment of European and East Asian countries on SPV at the } \\
\text { utility scale. }\end{array}$ & 3.00 & 0.70 & 3.70 & Ordinary \\
\hline & $\begin{array}{l}\text { C5: Fossil fuels-based } \\
\text { economy* }\end{array}$ & $\begin{array}{l}\text { General long-term direction to rely on fossil resources for } \\
\text { maximum export. }\end{array}$ & 1.50 & 6.90 & 8.40 & Ordinary \\
\hline & $\begin{array}{l}\mathrm{C}_{6}: \text { Fossil fuels export } \\
\text { income }\end{array}$ & $\begin{array}{l}\text { The rate of earnings from the exports of fossil fuels (crude oil, } \\
\text { natural gas, petroleum products, and potentially gasoline) [1]. }\end{array}$ & 2.30 & 0.90 & 3.20 & Ordinary \\
\hline & $\begin{array}{l}\mathrm{C}_{7} \text { : Declining global } \\
\text { equipment prices }\end{array}$ & Reductions in the purchase costs of solar panel equipment. & 0.00 & 2.60 & 2.60 & $\begin{array}{l}\text { Transmitt } \\
\text { er }\end{array}$ \\
\hline & $\begin{array}{l}\mathrm{C}_{8}: \text { Government } \\
\text { investment }^{*}\end{array}$ & Direct involvement of the government in on/off-grid projects. & 4.50 & 2.60 & 7.10 & Ordinary \\
\hline & $\mathrm{C}_{9}$ : Government support ${ }^{*}$ & $\begin{array}{l}\text { Government incentives (grant, rebates, and FiT) to stimulate } \\
\text { private and semi-private companies. }\end{array}$ & 3.50 & 6.10 & 9.60 & Ordinary \\
\hline & $\mathrm{C}_{10}$ : Investment risk ${ }^{*}$ & $\begin{array}{l}\text { Actual and perceived risks of an investment in the energy industry; } \\
\text { trust issues and uncertainties regarding payback period and } \\
\text { government policy changes; challenges regarding public sector } \\
\text { investment. }\end{array}$ & 5.70 & 3.60 & 9.30 & Ordinary \\
\hline & $\mathrm{C}_{11}$ : Oil price & $\begin{array}{l}\text { The global oil price that has a direct influence on the country's } \\
\text { economic growth. }\end{array}$ & 0.00 & 0.20 & 0.20 & $\begin{array}{l}\text { Transmitt } \\
\text { er }\end{array}$ \\
\hline & $\begin{array}{l}\mathrm{C}_{12}: \text { Private sector } \\
\text { involvement }\end{array}$ & $\begin{array}{l}\text { The willingness and motivation of the private sector to be } \\
\text { involved in solar projects. }\end{array}$ & 6.20 & 0.70 & 6.90 & Ordinary \\
\hline & $\mathrm{C}_{13}: \mathrm{O} \& \mathrm{M}$ cost & The cost associated with operational and maintenance expenses. & 1.70 & 1.00 & 2.70 & Ordinary \\
\hline & $\begin{array}{l}\mathrm{C}_{14}: \text { Solar installation } \\
\text { costs }\end{array}$ & $\begin{array}{l}\text { The costs associated with new SPV installations, including } \\
\text { acquisition, utilization, and connection to the grid. }\end{array}$ & 1.50 & 6.70 & 8.20 & Ordinary \\
\hline & $\mathrm{C}_{15}:$ Stability & Bankability and stability of the government economic sector. & 2.40 & 1.40 & 3.80 & Ordinary \\
\hline
\end{tabular}




\begin{tabular}{|c|c|c|c|c|c|c|}
\hline \multirow{2}{*}{ 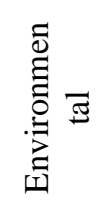 } & $\begin{array}{l}\mathrm{C}_{16}: \text { Environmental } \\
\text { concerns }\end{array}$ & $\begin{array}{l}\text { Responsibility and environmental values at the government level } \\
\text { or household level toward environmental protection. }\end{array}$ & 0.70 & 0.60 & 1.30 & Ordinary \\
\hline & $\begin{array}{l}\mathrm{C}_{17} \text { : Environmental } \\
\text { regulations on energy } \\
\text { consumption }\end{array}$ & $\begin{array}{l}\text { Related to pollution risks/costs. Adaptation to global conventions } \\
\text { e.g. United Nations Framework Convention on Climate Change } \\
\text { (UNFCCC). }\end{array}$ & 1.40 & 0.30 & 1.70 & Ordinary \\
\hline \multirow{2}{*}{ 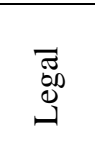 } & $\begin{array}{l}\mathrm{C}_{18} \text { : REs related laws and } \\
\text { regulations }\end{array}$ & $\begin{array}{l}\text { Government laws and legislation that facilitate/ hinder RE } \\
\text { projects. }\end{array}$ & 3.10 & 0.40 & 3.50 & Ordinary \\
\hline & $\begin{array}{l}\mathrm{C}_{19} \text { : Targeted subsidy } \\
\text { plan }\end{array}$ & $\begin{array}{l}\text { Iranian subsidy reform plan, amid at replacing subsidies on food } \\
\text { and energy ( } 80 \% \text { of total) with targeted social assistance. }\end{array}$ & 0.80 & 1.70 & 2.50 & Ordinary \\
\hline \multirow{6}{*}{ 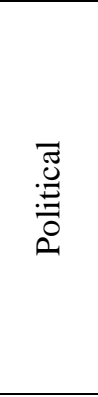 } & $\begin{array}{l}\mathrm{C}_{20} \text { : Energy export } \\
\text { security }\end{array}$ & $\begin{array}{l}\text { The capability and stability of exporting fossil fuels as the } \\
\text { primary source of revenues. }\end{array}$ & 1.50 & 1.90 & 3.40 & Ordinary \\
\hline & $\begin{array}{l}\mathrm{C}_{21} \text { : Energy } \\
\text { diversification strategy }\end{array}$ & $\begin{array}{l}\text { General policies to reduce dependence on fossil fuel revenues, } \\
\text { thus improving national energy security level. }\end{array}$ & 2.90 & 1.90 & 4.80 & Ordinary \\
\hline & $\mathrm{C}_{22}$ : Relations with EU & The long-run political relations with the EU countries. & 0.40 & 3.90 & 4.30 & Ordinary \\
\hline & $\mathrm{C}_{23}$ : Reinstated sanctions* & $\begin{array}{l}\text { The reimposition of the sanctions by the U.S. on Iran's energy } \\
\text { and economic sector. }\end{array}$ & 0.90 & 9.00 & 9.90 & Ordinary \\
\hline & $\mathrm{C}_{24}$ : Political risk & The perceived internal political threats by the private sector. & 1.40 & 2.40 & 3.80 & Ordinary \\
\hline & $\mathrm{C}_{25}$ : Political stability & $\begin{array}{l}\text { Stability and volatility in the region or the in relations with the } \\
\text { EU countries. }\end{array}$ & 1.80 & 0.20 & 2.00 & Ordinary \\
\hline \multirow{2}{*}{ 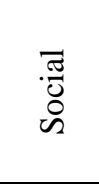 } & $\mathrm{C}_{26}$ : Social effects & $\begin{array}{l}\text { Job creation; the impact of easy access to electricity in remote } \\
\text { areas. }\end{array}$ & 2.20 & 0.00 & 2.20 & Receiver \\
\hline & $\mathrm{C}_{27}$ : Social acceptance & $\begin{array}{l}\text { Social influence and peer effects of existing adopters (such as } \\
\text { neighbors, friends, family, acquaintances, and colleagues) on } \\
\text { non-adopters at residential sector. }\end{array}$ & 1.50 & 0.10 & 1.60 & Ordinary \\
\hline \multirow{3}{*}{ 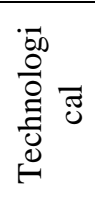 } & $\begin{array}{l}\mathrm{C}_{28}: \text { Lifespan and } \\
\text { reliability (durability) }\end{array}$ & $\begin{array}{l}\text { System life and technical reliability influencing total costs and } \\
\text { payback period. }\end{array}$ & 0.80 & 2.00 & 2.80 & Ordinary \\
\hline & $\mathrm{C}_{29}: \mathrm{R} \& \mathrm{D}$ & The contribution of research and development projects. & 4.90 & 0.60 & 5.50 & Ordinary \\
\hline & $\begin{array}{l}\mathrm{C}_{30} \text { : Technology } \\
\text { efficiency }\end{array}$ & $\begin{array}{l}\text { The higher efficiency of the technology through possible global } \\
\text { or country breakthrough. }\end{array}$ & 0.40 & 2.95 & 3.35 & Ordinary \\
\hline \multicolumn{2}{|c|}{$\mathrm{C}_{31}$ : Development of solar energy } & For the horizon 2030. & 6.55 & 0.20 & 6.75 & Ordinary \\
\hline
\end{tabular}

${ }^{*}$ Key concepts

\subsection{Scenario development}

There is a raising uncertainty over the contribution of SPV in the future of Iran's energy sector, which is attributed to several unstable conditions. The FCM generated in the workshops are exerted to test four plausible pathways for the 2030 horizon (Table 2). Iran's energy sector, and in particular solar, is government-driven, closely interconnected and profoundly affected by endogenous and exogenous drivers. Thus, the developed narratives are generalized to the energy sector, from which future solar development scenarios are extracted.

Table 2. Scenarios assumptions outlining possible futures of Iran's solar sector and their corresponding values on key concepts of the FCM model.

\begin{tabular}{|c|c|c|c|c|c|}
\hline Scenario name & $\begin{array}{l}\text { Cornered in a Dead- } \\
\text { End }\end{array}$ & At Wits' End & & Period of Tolerance & Blue Sky \\
\hline \multicolumn{6}{|l|}{ Outline of scenarios assumptions } \\
\hline Oil and gas export markets & Decrease (70\%-100\%) & $\begin{array}{l}\text { Decrease } \\
100 \%)\end{array}$ & $(70 \%-$ & Relatively unchanged & Increase (10-40\%) \\
\hline Relations with European countries & Break up & Cold & & Established partnership & Hand in hand \\
\hline $\begin{array}{l}\text { The share of REs from electricity } \\
\text { production }\end{array}$ & No change/decrease & No change & & Increase & Increase \\
\hline
\end{tabular}




\begin{tabular}{|c|c|c|c|c|}
\hline Foreign policy risks & High & High & Moderate & Low \\
\hline Effectiveness of sanctions & High & High & Moderate & Low \\
\hline U.S. policy on Iran & Further challenges & Further challenges & No change & Less challenge \\
\hline \multicolumn{5}{|c|}{ Implications on key concepts of the FCM model } \\
\hline $\mathrm{C}_{5}$ : Fossil fuels-based economy & More (fossil) focus & More (fossil) focus & No change & Transition to REs \\
\hline $\mathrm{C}_{8}$ : Government investment & Decrease & Decrease & No change & Increase \\
\hline $\mathrm{C}_{9}$ : Government support & No change & Increase & Increase & No change \\
\hline $\mathrm{C}_{10}$ : Investment risk & High & High & Low & Low \\
\hline $\mathrm{C}_{23}$ : Reinstated sanctions & Effective & Effective & Effective & Less/Removed \\
\hline
\end{tabular}

Disagreements over the country's nuclear program between Iran and five permanent members of the United Nations Security plus Germany resulted in international economic sanctions in 2011 [73]. Those sanctions targeting Iranian energy and financial sectors were removed following the nuclear agreement, known as the Joint Comprehensive Plan of Action (JCPOA) in 2015 [74]. The JCPOA effectively lasted for less than three years when the U.S. decided to unilaterally withdraw from the multilateral agreement in 2018 and reimpose secondary sanctions. Efforts to salvage the deal are currently being made by European members through establishing trade channel to Iran, the effectiveness of which remains to be seen in the upcoming months.

The promotion of promising REs is strongly affected by those political shifts and is subject to the participation of companies and investment injection [75, 76]. The first two narratives outline “Cornered in a Dead-End”, “At Wits’ End”, where RE development projects are at the highest risk by the political challenges, and oil exports revenues are at the lowest rate. The third scenario, "Period of Tolerance" signals resilience to the political adversity and challenges. The fourth projection, "Blue Sky”, assumes Iran's political scene retains a stable condition. In all scenarios, the level of awareness and knowledge of households are expected to grow, although that will not alone contribute to a strong intention to adopt solar technology. Worth mentioning is the chance that the exact nature of how future circumstances occurs is unlikely. What these pathways are pursuing is capturing plausible, rational explanatory narratives that can be further used in FCM to scrutinize the implications for the development of Iran's solar sector.

The first scenario, Cornered in Dead-End, is the worst possible trajectory for the solar industry. As high as is the political tensions, the remaining nuclear deal parties fail to preserve and maintain the financial trading channel. The resumption of economic sanctions (by the U.S.) proves to be effective, surging budget deficit and financial liability. The investment risks for solar companies escalate and available technology suppliers are limited while it is expected that most current development programs face a delay. The scenario assumes that the regional tensions witnessing a high level of controversy target policies to curb Iran's share in the global oil market. That stimulates the development of the national energy-intensive industries, which benefit from lowprice fossil resources as a competitive advantage. Under such circumstances, most attention is drawn to saving the marginal share of the international oil market, and at the same time meeting the increasing electricity demand by thermal power plants.

At Wits' End projects a similar political challenge and their adverse influences on RE projects. While struggling to keep its oil market share, the country slowly increases its natural gas market shares with limited LNG and mini-LNG shipments to India and China. Alternative resources are welcome by the government to alleviate the pressure on the national grid. Some limited policy incentives, including tax exemptions and improved legislations are provided for the promotion of solar although these are not strong drivers to encourage diffusion of the technology in the 
residential sector. The country has been attempting to reach the targeted plans in REs development programs (5\% of total electricity generation capacity) over a five-year period (Iran's $6^{\text {th }}$ national development plan). Still, state ownership is the leading national policy in energy industries to support bargaining power and flexibility of sovereignty. Consequently, utility investments in RE technologies remain largely limited. Besides, lack of privatization and the reluctance of foreign investors intensifies technology backwardness in the case of RE technologies.

Period of Tolerance describes a situation where the country strives to adapt to the sanctions. As the U.S. sanctions continue to constrain Iran's energy industry, there remain some ties between Iran and the European countries. This link is expected to slow down some tensions and provide low political and economic stability, which will contribute to the participation of a number of solar companies. The scenario assumes that the country will choose to follow capital absorption strategies. From the domestic perspective, the parliament facilitates the privatization process to attract private sector capital and capabilities to launch, operate and maintain RE resources centered by solar and wind energies. In the Period of Tolerance, the government endeavors to empower the private sector, playing as the regulator in the national energy market itself. That will see the government providing a favorable environment for RE development projects but does not imply any dramatic transition from fossil resources to REs.

The fourth scenario of Blue Sky is where Iran manages to successfully rehabilitate foreign relations with world powers and launches a new era of cooperation and partnership. The country follows strategies of alternative energy resources to diversify domestic energy suppliers and expand export potentials. Transition to clean resources is correlated with the direct involvement of the government in solar farm projects. At the domestic sector, the focus is mostly directed to remote areas with limited access to the electricity grid by providing generous incentives to promote solar home systems. Foreign investment and local human resources are two main drivers to follow national energy management strategies. In this situation, it is estimated that the RE sector contributes to $30 \%$ of total electricity supplied for residential and commercial sectors while fossil fuels remain the dominant sources for industry. In the Blue-sky scenario, REs' share of primary energy sources will multiply in the mid-term future; nevertheless, increasing domestic energy demand narrows the country's profit borders.

The five selected key concepts (section 2.4) are then linked to the narratives of scenarios. The value of key concepts in each storyline is set to increase, decrease, or remain unchanged under the developed scenarios, which is compared to the current status (Table 2). In Cornered in Dead-End, investment in solar is perceived as high risk $\left(\mathrm{C}_{10}=1\right)$, there is no change in government support while government investment will be lower than the current rate $\left(\mathrm{C}_{8}=0\right)$. The effects of sanctions will be severe $\left(\mathrm{C}_{23}=1\right)$ whereas there is a tendency toward amplifying fossil fuels $\left(\mathrm{C}_{5}=1\right)$. The implications of At Wits' End are the same as Cornered in Dead-End except for the supportive role of government $\left(\mathrm{C}_{9}=1\right)$. For Period of Tolerance, sanctions are still in place $\left(\mathrm{C}_{23}=1\right)$, but the sector is supported by the government $\left(\mathrm{C}_{9}=1\right)$ with lower investment risk $\left(\mathrm{C}_{10}=0\right)$. Blue-sky highlights transition toward renewable economy $\left(\mathrm{C}_{5}=1\right)$, government investment $\left(\mathrm{C}_{8}=1\right)$ and low risk $\left(\mathrm{C}_{10}=1\right)$. It is noteworthy that except for Blue Sky where sanctions are assumed to be removed $\left(\mathrm{C}_{23}=0\right)$, all three other scenarios underline persistence of these economic limitations. 


\section{FCM analysis}

This section describes the characteristics and structure of the FCM model, the sensitivity of the key concepts on the system, and scenario analysis. Before that, a short description of the main factors' specifications is discussed.

\subsection{Main factors}

Similar to concepts, main factors can absorb some characteristics when the value of their respective concepts are aggregated. Although they are not used in the simulations, they do provide insights into two notable general trends: First, how the factors' characteristics are defined (Fig. 13), and second, between which elements macro interactions occur (Fig. 14). As shown in Fig. 13a, the development of the solar sector is driven by economic and political factors. Social is solely dependent, legal is more of a receiver whereas environmental is autonomous. Economic factor has the highest centrality (4.82) but drops to second after political as the most potent driver $(2.34<3.02)$. When interpreting the attribute of factors, one should keep in mind the effect of selfloops. Concepts of the four factors interact with concepts within the same category (Fig. 14). As Fig. 13 (a-b) compares the in/outdegree values of factors taking the effects of self-loops into account, it becomes apparent that technological and legal are more interactive than others when the links only outside of the same elements count. A large proportion of total weights of economic concepts are self-loops (59\%) as it becomes more of a receiver than transmitter $(1.13>0.95)$.

At the center of the system is the economic factor that actively interacts with all others (Fig. 14). This factor generally acts as a transmitter but is a major receiver when it comes to political. This signifies the financial elements of the solar sector that are directly and heavily affected by political variations. Interestingly, legal and in particular, technological (e.g., R\&D activities) factors are the function of economic development. Also interesting is the absence of any linkage between environmental and social, and between social with legal factors. These indications on the demand side can be attributed to the insignificant level of pro-environmental norms of household's behavior for not pushing for the new, environmentally friendly technology.

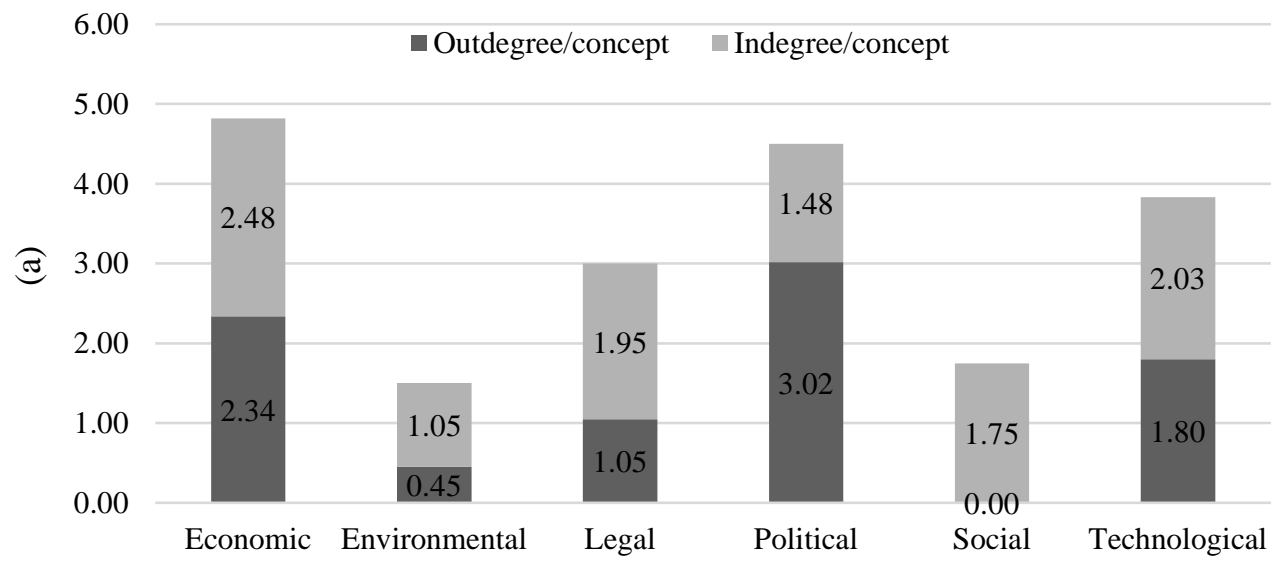




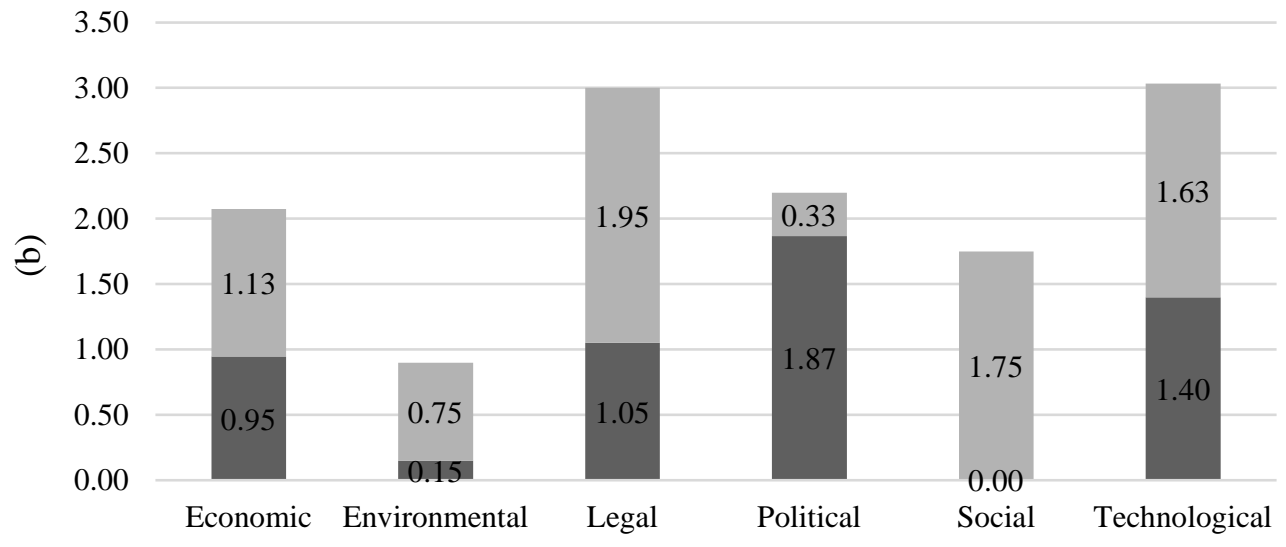

Fig. 13. Indegree and outdegree of main factors without $C_{31}$ links, (a) including and (b) excluding self-loops.

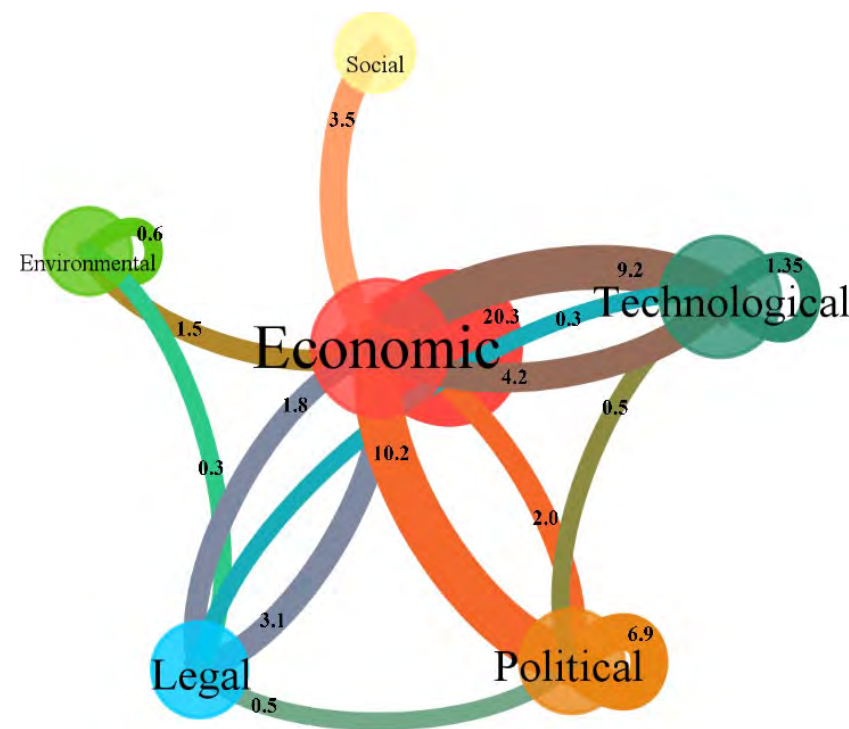

Fig. 14. The holistic interactions of six main factors comprising of 16 causal links. The values obtained using the absolute value of the total in/out-degree weight of all concepts (excluding $\mathrm{C}_{31}$ ) associated with each main factor.

\subsection{FCM structure and concepts characteristics}

The FCM model, consisting of 31 concepts was categorized into six main groups of factors. Economic holds the highest proportion with $48 \%$, while environmental, social, and legal factors have the lowest proportion at $6 \%$. Four of the key concepts come from economic $\left(\mathrm{C}_{5}, \mathrm{C}_{8}, \mathrm{C}_{9}, \mathrm{C}_{10}\right)$, one is political $\left(\mathrm{C}_{23}\right)$, and two $\left(\mathrm{C}_{5}\right.$ and $\left.\mathrm{C}_{23}\right)$ come from outside of the $\mathrm{RE}$ sector. The total links (135) are all regular except for one self-loop (energy demand) highlighting the independent increase of energy demand regardless of impact from other concepts. Fourteen concepts, nine economic, three political, and one from each of the social and technological factors, directly influence the goal, whereas the goal itself positively changes social acceptance $\left(\mathrm{C}_{27}\right)$. This 
influence can be perceived as the social influence (from peers and media) on non-adopters. In general, development of solar sector heavily relies on the active role of fossil fuels-related concepts $\left(C_{5}, C_{6}, C_{11}, C_{20}, C_{21}\right)$. Some general specifications of the developed model are provided in Table 3.

Table 3. Specifications of the FCM model.

\begin{tabular}{ll}
\hline Index & Value \\
\hline Positive (negative) connections & $59(76)$ \\
Density & 0.145 \\
Hierarchy index & 0.062 \\
Average degree & 4.355 \\
Average weighted degree & 2.185 \\
Modularity & 0.273 \\
Average clustering coefficient & 0.279 \\
Average path length & 3.274 \\
\hline
\end{tabular}

Looking closely into the concepts' characteristics (Table 1), "reinstated sanctions" is the most central parameter impinging the system followed by "fossil fuels export economy", "solar installation costs" and "government support"; though the latter is effected by (receiver) than others. The level of research into the solar sector $\left(\mathrm{C}_{29}\right)$ relies on other parameters, similar to "government investment", which has high centrality but is the receiver than the transmitter (4.5>2.6). "Private sector involvement" is an essential player in solar diffusion where its level of involvement relies on other sectors and is a passive element in general. Notably, the pressure to transition toward clean energy imposed by environmental degradation is weak ("environmental concerns" with 1.3 of centrality), whereas both "oil price" and "electricity price" play an accessory role within the network.

Fig. 15 illustrates three indices that facilitate a better understanding of the roles of concepts in the system by highlighting their properties. Closeness centrality is the average distance of a concept to others in a network; eigen centrality as the extension of degree centrality, measures the influence of a concept in a system; and harmonic centrality is similar to closeness centrality but computes unconnected nodes as well (see [77] for more description and mathematical equations of the indices). The "social effects" $\left(\mathrm{C}_{26}\right)$ is isolated in the system while "social acceptance" $\left(\mathrm{C}_{27}\right)$ has the highest closeness, meaning that it is dynamically in connection with other nodes. "Private sector involvement" $\left(\mathrm{C}_{12}\right)$ and "R\&D" $\left(\mathrm{C}_{29}\right)$, while having low closeness centrality, strongly influence the system. As for the key concepts determined by experts, "fossil fuels based economy" $\left(\mathrm{C}_{5}\right)$ and "reinstated sanctions" $\left(\mathrm{C}_{23}\right)$ are the highest in harmonic centrality although the latter is low in eigen centrality. A broader view, it can be interpreted that the network is connected since the results of closeness and harmonic centrality are similar. More indices and properties of the concepts under study can be found in Supplementary Data. 


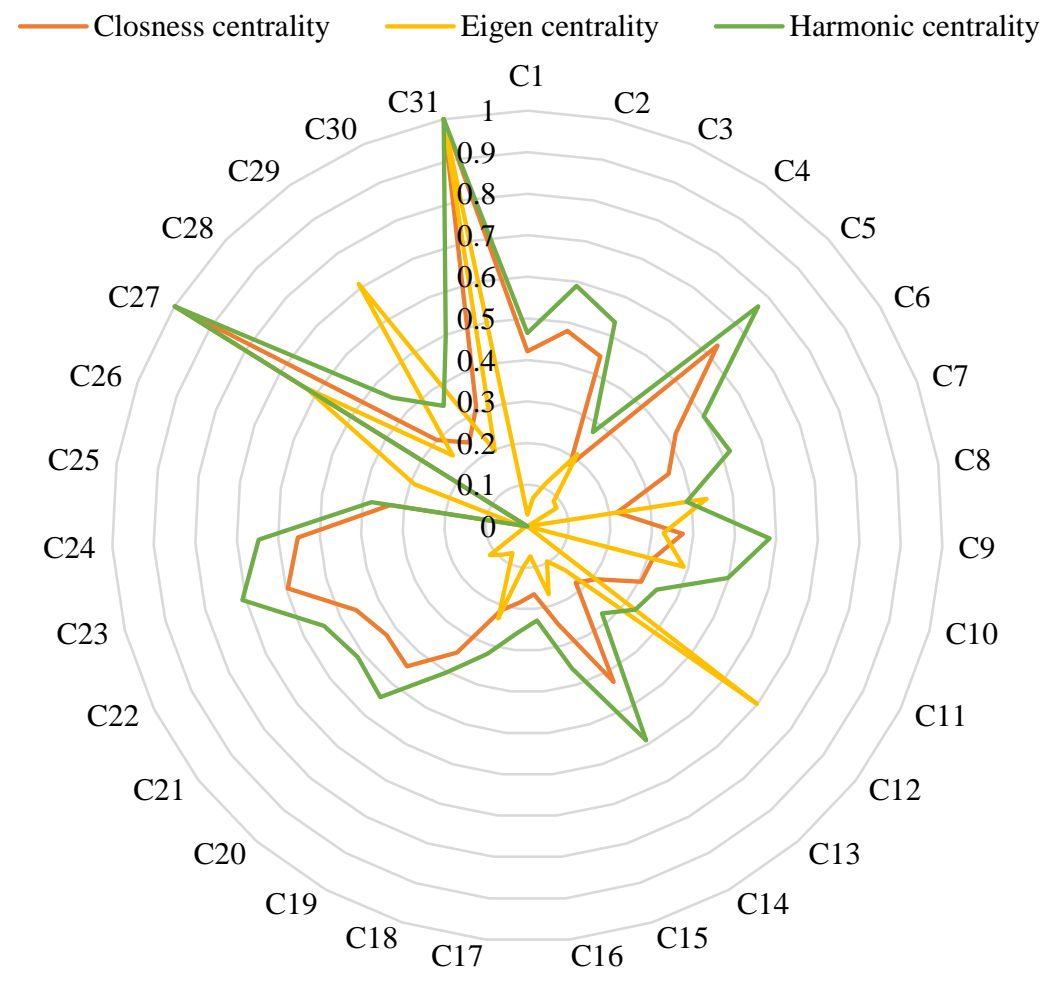

Fig. 15. The influence and role of each concept in the system using three indices.

\subsection{The sensitivity of key concepts}

A sensitivity analysis of the system is tested in this section that helps in grasping the impact and the rate of change in the value of the key concepts on other variables and the goal. To do so, the model is first run to see the results at the initial steady state (baseline scenario), which is used in both sensitivity and scenario analysis. The outcome of the steady state with no intervention and starting state vectors at 1 is obtained after less than 20 iterations (Fig. 16). The results are interpreted by comparing the relative change between this baseline scenario and the new steady state. Worth mentioning is that negative change in the value of "development of solar energy" $\left(\mathrm{C}_{31}\right)$ is regarded as deceleration in deployment and diffusion of solar energy compared to the current state; conversely, the positive change reflects that the development process of the sector continues at a higher level than present. 

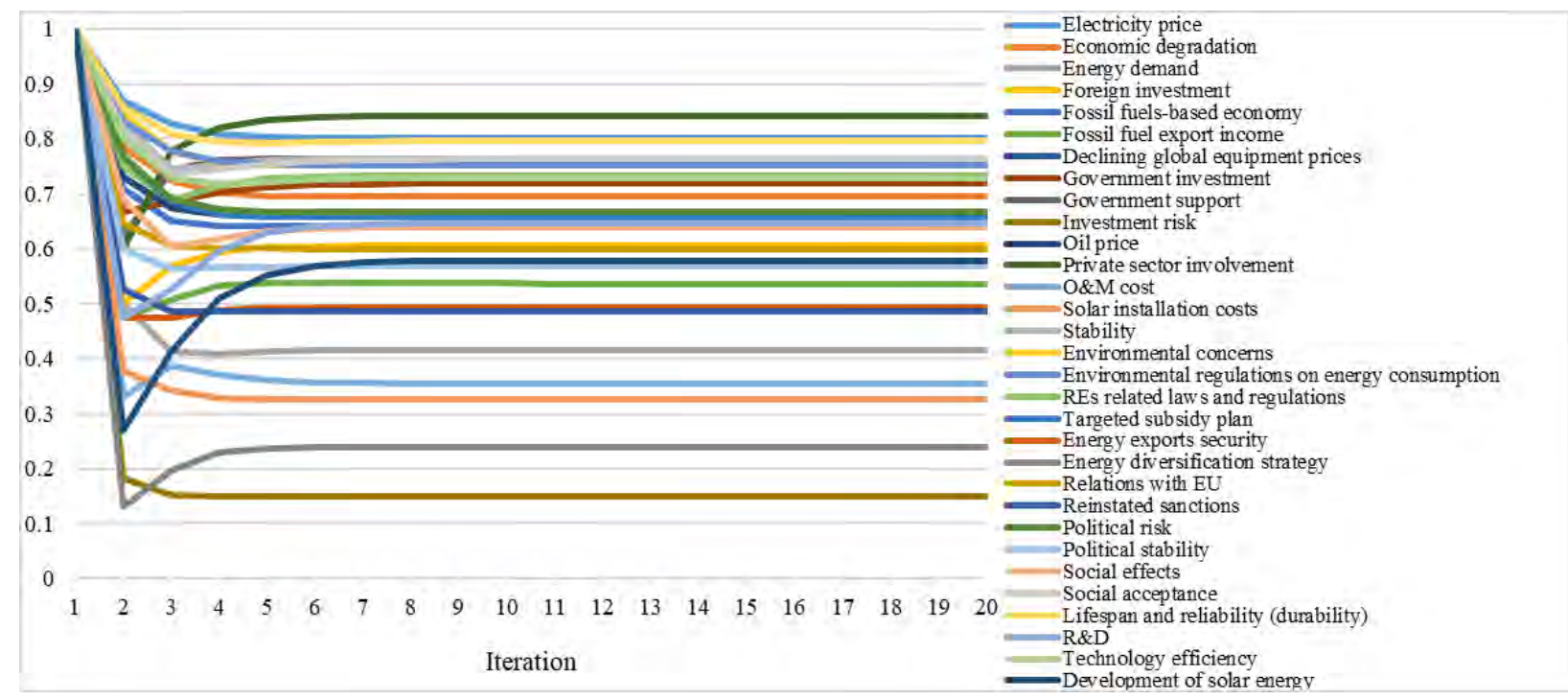

Fig. 16. The steady state (baseline scenario) of concepts with no policy intervention (no clamping). $\mathrm{C}_{31}$ stabilized at 0.578 at the end of the iterations.

The level of change in the value of concepts when the key concepts were clamped to zero (one by one) is illustrated in Fig. 17. The system shows the highest sensitivity when "fossil fuels based economy" and "reinstated sanctions" are clamped to zero. The value of fourteen concepts sees changes (more than $>5 \%$ compared to the initial values) in each exploration. The decrease in the former $\left(\mathrm{C}_{5}\right)$, while expectedly leading to a reduction in fossil fuels export income (-16\%), substantially reduces the level of "investment risk" (-30\%). "R\&D" activities are positively impacted (+21\%), whereas energy diversification sees the greatest influence. The removal of sanctions (or when $\mathrm{C}_{23}$ is clamped to 0 ) would also stimulate energy transition $\left(\mathrm{C}_{21}\right)$. The concept has the strongest impact on most economic elements, and similarly other political concepts, which is unsurprising given the similar nature of concepts.

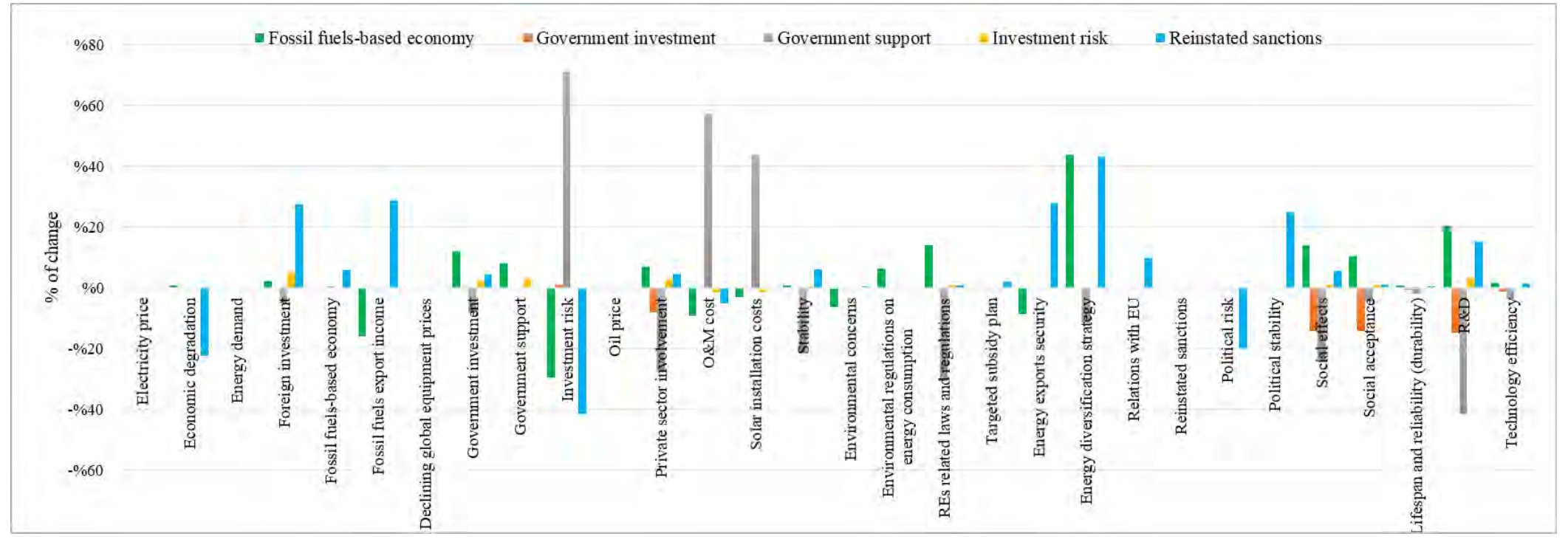


Fig. 17. The rate of change of the 30 concepts by clamping the five key concepts to zero compared to the initial steady state (baseline scenario) (Fig. 16). The simulations were performed separately for each key concept.

When clamping investment risk to 0, concepts remain highly stabilized except for "foreign investment" and "R\&D". These are slightly affected, although "investment risk" causes an adverse effect on goal when it is turned on (starting point of sensitivity test in Fig. 18). "Investment risk" is also most stimulated by other concepts, notably facing changes by $\mathrm{C}_{8}, \mathrm{C}_{23}$, and $\mathrm{C}_{5}$ at around $71 \%$, $-41 \%$, and $-29 \%$, respectively. The lack of government investment $\left(\mathrm{C}_{8}\right.$ clamped to 0 ) creates no positive change to the system, but negatively exacerbates social factors, and to some level "R\&D" and "private sector involvement". Its adverse effect on the goal is also only second to the "investment risk" (comparing $C_{8}$ clamped to 1 against $\mathrm{C}_{10}$ when is clamped to 0) (Fig. 18). As "financial support and incentives" plunge ( $\mathrm{C}_{9}$ clamped to 0 ), public sector investment face high risk, purchase price and "O\&M cost” also significantly increases.

The general trend reveals that reinstated sanctions and fossil fuels-based economy exert a strong control on the dynamics of the system. However, a decrease in government support delivers more intense change to the functioning of the system despite influencing a smaller number of concepts. The next sensitivity analysis is observing the relative changes in solar development under different values of key concepts (Fig. 18). Despite being heavily influenced by the absence of government support (-43\%) and investment (-34\%), there is only a slight increase in the development of solar, if they are in place. Conversely, the vulnerability of solar deployment is at its highest by high risk $(-48 \%)$. This conveys the notion that industries and households would be reluctant to seriously consider solar investment when the perceived financial risk is high, and uncertainties exist regarding the commitment of government or local suppliers. The general direction of the longterm plan ( $\mathrm{C}_{5}$ to 0$)$ to shift toward alternative resources would reinforce the solar sector. Interestingly, this strategic shift is expected to be more important than lifting sanctions ( $\mathrm{C}_{23}$ to 0$)$ (38\%>23\%). 


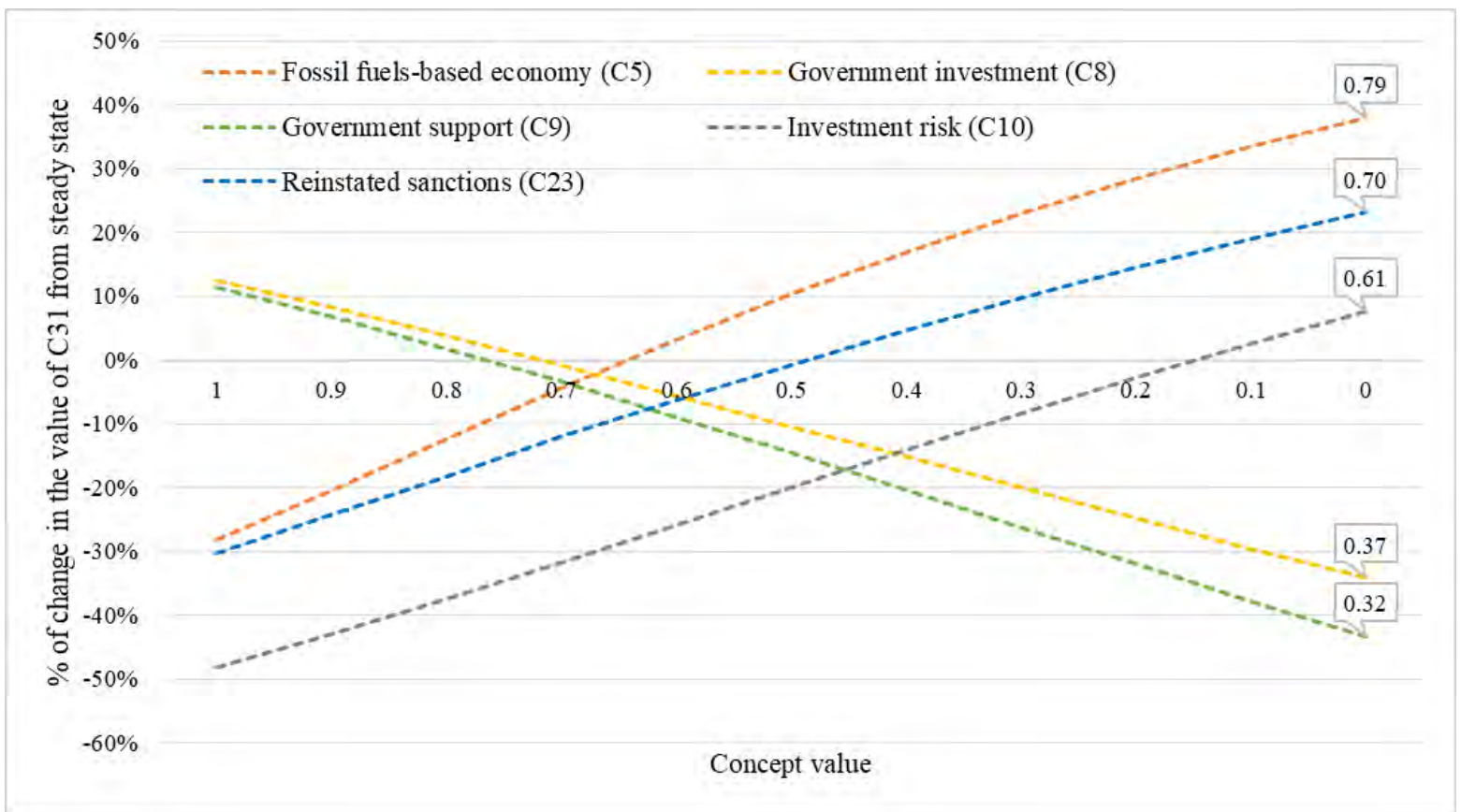

Fig. 18. The sensitivity of the goal $\left(\mathrm{C}_{31}\right)$ to the changes in the value of the key concepts clamped from 1 to 0 . The percentage posits a change relative to the initial state value of $\mathrm{C}_{31}(0.578)$. Numbers in the callout represent the value of $\mathrm{C}_{31}$ at the end of the simulation when the respective key concept is clamped to 0 .

\subsection{Scenario results}

The simulation results of four generated scenarios regarding the development of Iran's solar sector are presented (Fig. 19). Recalling that, the negative value means that the development of the solar industry at the residential and utility sector proceeds at a slower pace, i.e., it has negative acceleration and vice versa. A general trend from the worst-case scenario (Cornered in a DeadEnd) to the best case (Blue Sky) manifests a sharp setback to a decent positive acceleration in the development of the solar sector. The gap in these predictions is as big as $140 \%$, which unfolds highly uncertain, varied futures. A major breakthrough in the diffusion of solar is not expected in any trajectory, whereas in only Blue Sky, a befitting acceleration in the processing of solar projects is envisioned. Except for Period of Tolerance, the rates of development can see swift changes. 


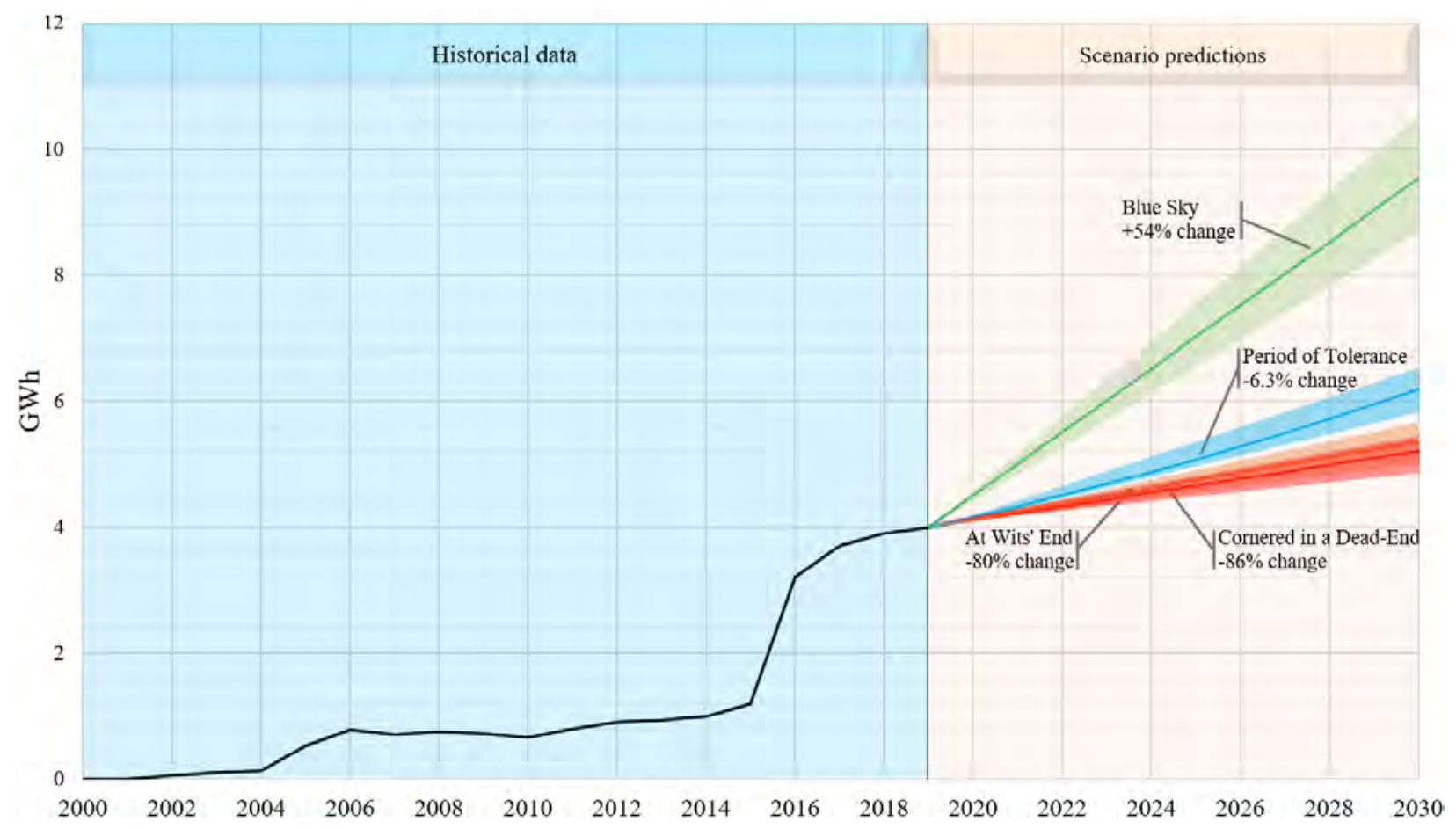

Fig. 19. The simulation results (in number). The graphical trends that are estimated based on the average growth of the past two years, are for display purposes only and should be interpreted qualitatively.

By 2030, both Cornered in a Dead-End and At Wits' End scenarios anticipate that the development processes will be at a much slower pace than the current rate. Under these two scenarios, the acceleration in the deployment trend of the solar sector decelerates by $86 \%$ and $80 \%$, respectively, reflecting complications with providing the required budget and with isolated solar companies which may shun the projects. Any new development project under these projections will be practically abandoned. The existence of government support in At Wits' End is only going to make a marginal difference (6\%) compared to Cornered in a Dead-End. Period of Tolerance assumes there will not be a significant disparity between the current trend of deployment and future projection (-6.3\%). This scenario is an optimistic supposition of ineffective sanctions. Considering no dramatic change in the general direction of the economy, the full support of the government under no salient investment risk can only hinder deceleration under the persistence of sanctions. That also suggests, though, that the solar sector is likely to implement effective mechanisms against exogenous variations using endogenous potentials. In Blue Sky, the solar sector benefits from the facilitated conditions to speed up development by $54 \%$. The positive response reflects the capability of the government to directly intervene, which occurs only when sanctions become ineffective (or removed) and the government shifts from a fossil fuels based economy.

The dynamics of the systems change markedly under three scenarios. The implications of Cornered in a Dead-End and At Wits' End disrupt the steady state by $22.75 \%$ and $19.65 \%$, respectively (refer to Supplementary Data). The rate of change for Blue Sky is also high (16.37) whereas Period of Tolerance perceives less change (9.7\%). Although the average absolute change in Blue Sky is lower than the two, the more concepts are expected to change. Of the 31 concepts, 19, 18, 16, and 13 change (>5\%) in Blue Sky, Cornered in a Dead-End, At Wits' End, and the 
Period of Tolerance, respectively. The variations in these scenarios are mainly driven by the dominating political concepts. The prevailing notion of the simulation results is of a high possibility of change in the system, as the current dynamics of the system is likely to change from the current behavior. Whether there is an escalation (Blue Sky) or decline (Cornered in a DeadEnd and At Wits' End), the system is likely to face change. That conveys the importance and role of concepts can also change, resulting in the emerging behavior of concepts in a new paradigm.

\section{Discussion and conclusion}

This study developed an FCM methodology aimed at exploring the characteristics and the foreseeable futures of SPV development in Iran. The relevant and influential concepts were identified in three layers of literature review, survey, and experts' finalization. The 31 determined concepts classified into six (PESTEL) categories highlight that the development of SPV is dominated by economic and political concepts having strong relations between each other and with technical while social is interpreted by other categories. Focusing on five key concepts, it was shown that fossil fuels-based economy and reinstated sanctions transform the stability of the system mostly. The growth rate is also primarily affected when the investment is risky. To further explore the plausible projections of the SPV development, four scenarios were tested for the horizon 2030. Two scenarios “Cornered in a Dead-End" and "At Wits' End" predict deceleration in the deployment trend; "Period of Tolerance" scenario assumes no dramatic change, while only "Blue Sky" scenario projects a decent acceleration in the development process of the SPV sector in the country. The overall results suggested that it is unlikely the sector witnesses a major advance unless there is a significant shift in the political and economic sectors.

The outcome that FCM model also reveals that the characteristics of Iran's SPV development are: highly uncertain, driven by proactive political and economic parameters, influenced by exogenous factors out of RE sector, and vulnerable to the external perturbs that change the dynamics of the system massively. In no scenario the long-term visions for the on-grid electricity generation by SPV is likely to be fulfilled. The similar results of two scenarios (Cornered in DeadEnd and At Wits' End) imply the higher possibility of a declining trend if the current political restrictions are to be continued. A general observation from scenario results is that, when there are sanctions in effect, the sector fails to escalate from the current rate. Under current conditions, the Blue-sky scenario seems far-fetched since it requires the occurrence of major simultaneous shifts in political and energy policy direction. However, the experience of swift changes in the shorttime interval does not rule out a similar projection of the Blue Sky in the long term.

Three observations can be drawn up about the outcome and use of the FCM. First, the developed scenarios were not managerial interventions of SPV adoption, but possible futures of what could emerge, in which the government may or may not play a role. The scenarios also postulated that the diffusion of SPV in the study area does not primarily rely on the decision of households, not at least by 2030. Residential sector at the macro level is perceived passive, and the adoption behavior is less important where it is waiting for generous incentives to close the gap between solar and grid electricity. A question remains as to what extent the emerging trend deviates if the payback period becomes within the acceptable range. It has been ascertained that the direct financial incentives are the key impediment to the government grappling with making the innovation affordable for the residential consumers. Interesting to analyze is the effectiveness of indirect policies, whether be intentional or unintentional, that would rapidly reduce the payback 
period. A case in point refers to the growth in the price of conventional electricity resources, which along with approaching the grid parity, can stimulate the adopters' motivation [78]. If that is the case, the radical microbehaviors might surge the diffusion rate and make their mark at the top level. This necessitates the provision of demand-side insights through the bottom-up analysis to complement the model implemented here.

Second, looking into the sector, the outline of the development and precedence of solar energy over other renewables seems sketchy and vague [79]. Once resolved, another intrinstic challenge for the sector would be answering how to sustain the resource funding chain, and the extent to which the government is willing to sacrifice to promote the technology. The scenarios emphasized on the uncertainty surrounding the future but did not debate on the countermeasures to cope with them. Designing effective strategies that are robust and resilient in response to these turbulences is the next agenda.

The last viewpoint is on the characteristics of the developed FCM. The exploited concepts covered much of the relevant areas. It should be acknowledged though that, they were less detailed, which was inevitable to provide a coverage for such a broad topic. More attention can be drawn to the concepts that encompass sub-concepts and their detailed attributes; and then building multilayer cognitive maps [80]. In this direction, linking optimization and linear models into the FCM in the form of integrated assessment modeling for appraising the economic, predictable variables like electricity price can be useful [81]. Communication and learning tools by FCMs can also yield tacit knowledge a better understanding of the experts in the development of a more structured model [82]. Similarly, narratives were centralized primarily at the exogenous econ-political facets, although they were just a few possibilities that may occur. Extensions of these narratives can dig deeper into the technical and social evolvements.

\section{Appendix A. Supplementary data}

The survey questionnaire, characteristics of the concepts, the rate of changes of concepts and main factors in the scenarios can be found at supplementary data.

\section{References}

[1] Alipour M, Hafezi R, Ervural B, Kaviani MA, Kabak Ö. Long-term policy evaluation: Application of a new robust decision framework for Iran's energy exports security. Energy. 2018. [2] Alipour M, Sheykhan A. A vision for Iran's fuel cell and hydrogen development. International journal of environmental science and technology. 2017;14:193-210.

[3] U.S. Department of Energy, National Renewable Energy Laboratory (NREL). Available from: https://catalog.data.gov/dataset/solar-resources-by-class-and-country (Accessed November 2018). 2018.

[4] Gorjian S, Zadeh BN, Eltrop L, Shamshiri RR, Amanlou Y. Solar photovoltaic power generation in Iran: Development, policies, and barriers. Renewable and Sustainable Energy Reviews. 2019;106:110-23.

[5] Solargis. (C) 2017 The world Bank.

[6] Agency IE. Electricity information 2018. 2018.

[7] Louis) FFRBoS. Economic Research. 2019. 
[8] Ajzen I. The theory of planned behavior. Organizational behavior and human decision processes. 1991;50:179-211.

[9] Suganthi L, Samuel AA. Energy models for demand forecasting-A review. Renewable and sustainable energy reviews. 2012;16:1223-40.

[10] Jebaraj S, Iniyan S. A review of energy models. Renewable and sustainable energy reviews. 2006;10:281-311.

[11] Amer M, Daim TU, Jetter A. A review of scenario planning. Futures. 2013;46:23-40.

[12] Swan LG, Ugursal VI. Modeling of end-use energy consumption in the residential sector: A review of modeling techniques. Renewable and sustainable energy reviews. 2009;13:1819-35.

[13] Zhao J, Mazhari E, Celik N, Son Y-J. Hybrid agent-based simulation for policy evaluation of solar power generation systems. Simulation Modelling Practice and Theory. 2011;19:2189-205.

[14] Baur L, Uriona M. Diffusion of photovoltaic technology in Germany: A sustainable success or an illusion driven by guaranteed feed-in tariffs? Energy. 2018;150:289-98.

[15] Ahmed A, Khalid M. A review on the selected applications of forecasting models in renewable power systems. Renewable and Sustainable Energy Reviews. 2019;100:9-21.

[16] Wang G, Zhang Q, Li Y, Li H. Policy simulation for promoting residential PV considering anecdotal information exchanges based on social network modelling. Applied energy. 2018;223:110.

[17] Palmer J, Sorda G, Madlener R. Modeling the diffusion of residential photovoltaic systems in italy: An agent-based simulation. Technological Forecasting and Social Change. 2015;99:106-31. [18] Adepetu A, Alyousef A, Keshav S, de Meer H. Comparing solar photovoltaic and battery adoption in Ontario and Germany: an agent-based approach. Energy Informatics. 2018;1:6.

[19] Feng Y, Chen S, Zhang L. System dynamics modeling for urban energy consumption and CO2 emissions: A case study of Beijing, China. Ecological Modelling. 2013;252:44-52.

[20] Aslani A, Helo P, Naaranoja M. Role of renewable energy policies in energy dependency in Finland: System dynamics approach. Applied Energy. 2014;113:758-65.

[21] Doukas H, Nikas A. Decision support models in climate policy. European Journal of Operational Research. 2019.

[22] Oria PA, Alaii J, Ayugi M, Takken W, Leeuwis C. Combining malaria control with house electrification: adherence to recommended behaviours for proper deployment of solar-powered mosquito trapping systems, Rusinga Island, western Kenya. Tropical Medicine \& International Health. 2015;20:1048-56.

[23] Schoemaker PJ. Scenario planning: a tool for strategic thinking. Sloan management review. 1995;36:25-50.

[24] Amer M, Jetter A, Daim T. Development of fuzzy cognitive map (FCM)-based scenarios for wind energy. International Journal of Energy Sector Management. 2011;5:564-84.

[25] Ziv G, Watson E, Young D, Howard DC, Larcom ST, Tanentzap AJ. The potential impact of Brexit on the energy, water and food nexus in the UK: A fuzzy cognitive mapping approach. Applied Energy. 2018;210:487-98.

[26] Papageorgiou EI, Hatwágner MF, Buruzs A, Kóczy LT. A concept reduction approach for fuzzy cognitive map models in decision making and management. Neurocomputing. 2017;232:1633.

[27] Case DM, Stylios CD. Fuzzy Cognitive Map to model project management problems. Fuzzy Information Processing Society (NAFIPS), 2016 Annual Conference of the North American: IEEE; 2016. p. 1-6. 
[28] Biloslavo R, Dolinsek S. Scenario planning for climate strategies development by integrating group Delphi, AHP and dynamic fuzzy cognitive maps. Management of Engineering \& Technology, 2008 PICMET 2008 Portland International Conference on: IEEE; 2008. p. 1103-11. [29] Anezakis V-D, Dermetzis K, Iliadis L, Spartalis S. Fuzzy cognitive maps for long-term prognosis of the evolution of atmospheric pollution, based on climate change scenarios: the case of Athens. International Conference on Computational Collective Intelligence: Springer; 2016. p. 175-86.

[30] Solana-Gutiérrez J, Rincón G, Alonso C, García-de-Jalón D. Using fuzzy cognitive maps for predicting river management responses: A case study of the Esla River basin, Spain. Ecological Modelling. 2017;360:260-9.

[31] Kontogianni AD, Papageorgiou EI, Tourkolias C. How do you perceive environmental change? Fuzzy Cognitive Mapping informing stakeholder analysis for environmental policy making and non-market valuation. Applied Soft Computing. 2012;12:3725-35.

[32] Kok K. The potential of Fuzzy Cognitive Maps for semi-quantitative scenario development, with an example from Brazil. Global Environmental Change. 2009;19:122-33.

[33] Mourhir A, Papageorgiou EI, Kokkinos K, Rachidi T. Exploring precision farming scenarios using fuzzy cognitive maps. Sustainability. 2017;9:1241.

[34] Abbar S, Boumaiza A, Mohandes N, Sanfilippo A, Ieee. Modeling Innovation Diffusion for Renewable Energy Technologies in City Neighborhoods. 2018 9th International Renewable Energy Congress2018.

[35] Lorenz S, Martinez-Fernández V, Alonso C, Mosselman E, de Jalón DG, del Tánago MG, et al. Fuzzy cognitive mapping for predicting hydromorphological responses to multiple pressures in rivers. Journal of applied ecology. 2016;53:559-66.

[36] Kyriakarakos G, Patlitzianas K, Damasiotis M, Papastefanakis D. A fuzzy cognitive maps decision support system for renewables local planning. Renewable and Sustainable Energy Reviews. 2014;39:209-22.

[37] Papageorgiou EI, Froelich W. Multi-step prediction of pulmonary infection with the use of evolutionary fuzzy cognitive maps. Neurocomputing. 2012;92:28-35.

[38] Iakovidis DK, Papageorgiou E. Intuitionistic fuzzy cognitive maps for medical decision making. IEEE Transactions on Information Technology in Biomedicine. 2011;15:100-7.

[39] Anninou AP, Groumpos PP, Panagiotis P. Modeling health diseases using competitive fuzzy cognitive maps. IFIP International Conference on Artificial Intelligence Applications and Innovations: Springer; 2013. p. 88-95.

[40] Stach W, Kurgan LA, Pedrycz W. Numerical and linguistic prediction of time series with the use of fuzzy cognitive maps. IEEE Transactions on Fuzzy Systems. 2008;16:61-72.

[41] Kim J, Han M, Lee Y, Park Y. Futuristic data-driven scenario building: Incorporating text mining and fuzzy association rule mining into fuzzy cognitive map. Expert Systems with Applications. 2016;57:311-23.

[42] Vidal R, Salmeron JL, Mena A, Chulvi V. Fuzzy cognitive map-based selection of TRIZ (theory of inventive problem solving) trends for eco-innovation of ceramic industry products. Journal of Cleaner Production. 2015;107:202-14.

[43] Devisscher T, Boyd E, Malhi Y. Anticipating future risk in social-ecological systems using fuzzy cognitive mapping: the case of wildfire in the Chiquitania, Bolivia. Ecology and Society. 2016;21.

[44] Osoba OA, Kosko B. Fuzzy cognitive maps of public support for insurgency and terrorism. The Journal of Defense Modeling and Simulation. 2017;14:17-32. 
[45] Alizadeh R, Lund PD, Beynaghi A, Abolghasemi M, Maknoon R. An integrated scenariobased robust planning approach for foresight and strategic management with application to energy industry. Technological Forecasting and Social Change. 2016;104:162-71.

[46] Chaharsooghi S, Rezaei M, Alipour M. Iran's energy scenarios on a 20-year vision. International journal of environmental science and technology. 2015;12:3701-18.

[47] Moshiri S, Atabi F, Hassan Panjehshahi M, Lechtenböehmer S. Long run energy demand in Iran: a scenario analysis. International Journal of Energy Sector Management. 2012;6:120-44.

[48] Abbaszadeh P, Maleki A, Alipour M, Maman YK. Iran's oil development scenarios by 2025. Energy policy. 2013;56:612-22.

[49] Bahrami M, Abbaszadeh P. Development a scenario-based model for Iran' s energy future. Renewable and Sustainable Energy Reviews. 2016;62:963-70.

[50] Axelrod R. Structure of decision: The cognitive maps of political elites: Princeton university press; 2015.

[51] Amirkhani A, Papageorgiou EI, Mosavi MR, Mohammadi K. A novel medical decision support system based on fuzzy cognitive maps enhanced by intuitive and learning capabilities for modeling uncertainty. Applied Mathematics and Computation. 2018;337:562-82.

[52] Kosko B. Fuzzy cognitive maps. International journal of man-machine studies. 1986;24:6575.

[53] Groumpos PP. Fuzzy cognitive maps: Basic theories and their application to complex systems. Fuzzy cognitive maps: Springer; 2010. p. 1-22.

[54] Papageorgiou EI, Subramanian J, Karmegam A, Papandrianos N. A risk management model for familial breast cancer: A new application using Fuzzy Cognitive Map method. Computer methods and programs in biomedicine. 2015;122:123-35.

[55] Nikas A, Doukas H. Developing robust climate policies: a fuzzy cognitive map approach. Robustness analysis in decision aiding, optimization, and analytics: Springer; 2016. p. 239-63.

[56] Papageorgiou EI. Fuzzy cognitive maps for applied sciences and engineering: from fundamentals to extensions and learning algorithms: Springer Science \& Business Media; 2013. [57] Amer M, Daim TU, Jetter A. Technology roadmap through fuzzy cognitive map-based scenarios: the case of wind energy sector of a developing country. Technology Analysis \& Strategic Management. 2016;28:131-55.

[58] Alipour M, Hafezi R, Amer M, Akhavan A. A new hybrid fuzzy cognitive map-based scenario planning approach for Iran's oil production pathways in the post-sanction period. Energy. 2017;135:851-64.

[59] Papageorgiou EI, Stylios CD, Groumpos PP. An integrated two-level hierarchical system for decision making in radiation therapy based on fuzzy cognitive maps. IEEE Transactions on Biomedical Engineering. 2003;50:1326-39.

[60] Papageorgiou E, Groumpos P. A new hybrid learning algorithm for fuzzy cognitive maps learning. Applied Soft Computing. 2005;5:409-31.

[61] Jetter A, Schweinfort W. Building scenarios with Fuzzy Cognitive Maps: An exploratory study of solar energy. Futures. 2011;43:52-66.

[62] Brandes U, Wagner D. Analysis and visualization of social networks. Graph drawing software: Springer; 2004. p. 321-40.

[63] Gray SA, Gray S, Cox LJ, Henly-Shepard S. Mental modeler: a fuzzy-logic cognitive mapping modeling tool for adaptive environmental management. 2013 46th Hawaii International Conference on System Sciences: IEEE; 2013. p. 965-73. 
[64] Bachhofer M, Wildenberg,M. FCMappers - Disconnecting the Missing Link. Available from: http://www.fcmappers.net/joomla/index.php. 2019.

[65] Nikas A, Ntanos E, Doukas H. A semi-quantitative modelling application for assessing energy efficiency strategies. Applied Soft Computing. 2019;76:140-55.

[66] Nápoles G, Leon M, Grau I, Vanhoof K. Fuzzy cognitive maps tool for scenario analysis and pattern classification. 2017 IEEE 29th International Conference on Tools with Artificial Intelligence (ICTAI): IEEE; 2017. p. 644-51.

[67] Margaritis M, Stylios C, Groumpos P. Fuzzy cognitive map software. 10th International Conference on Software, Telecommunications and Computer Networks SoftCom2002. p. 8-11.

[68] De Franciscis D. JFCM: A Java Library for FuzzyCognitive Maps. Fuzzy Cognitive Maps for Applied Sciences and Engineering: Springer; 2014. p. 199-220.

[69] Glykas M. Fuzzy cognitive maps: Advances in theory, methodologies, tools and applications: Springer; 2010.

[70] FCM WIZARD www.fcmwizard.com. 2017.

[71] Gray S, Gagnon A, Gray S, O'Dwyer B, O'Mahony C, Muir D, et al. Are coastal managers detecting the problem? Assessing stakeholder perception of climate vulnerability using Fuzzy Cognitive Mapping. Ocean \& Coastal Management. 2014;94:74-89.

[72] Özesmi U, Özesmi SL. Ecological models based on people’s knowledge: a multi-step fuzzy cognitive mapping approach. Ecological modelling. 2004;176:43-64.

[73] Hafezi R, Akhavan A, Pakseresht S, Wood DA. A Layered Uncertainties Scenario Synthesizing (LUSS) model applied to evaluate multiple potential long-run outcomes for Iran's natural gas exports. Energy. 2019;169:646-59.

[74] Skretas SB, Papadopoulos DP. A general and systematic procedure for the technical/economic/socio-environmental assessment of residential stand alone autonomous PV systems: Application to a small-scale rsaaps installed in the city of Xanthi/Thrace, Greece. Journal of Electrical Engineering-Elektrotechnicky Casopis. 2007;58:351-62.

[75] Aghahosseini A, Bogdanov D, Ghorbani N, Breyer C. Analysis of 100\% renewable energy for Iran in 2030: integrating solar PV, wind energy and storage. International Journal of Environmental Science and Technology. 2018;15:17-36.

[76] Korsavi SS, Zomorodian ZS, Tahsildoost M. Energy and economic performance of rooftop PV panels in the hot and dry climate of Iran. Journal of cleaner production. 2018;174:1204-14.

[77] Rochat Y. Closeness centrality extended to unconnected graphs: The harmonic centrality index. 2009.

[78] Karakaya E, Hidalgo A, Nuur C. Motivators for adoption of photovoltaic systems at grid parity: A case study from Southern Germany. Renewable and Sustainable Energy Reviews. 2015;43:1090-8.

[79] Alipour M, Alighaleh S, Hafezi R, Omranievardi M. A new hybrid decision framework for prioritizing funding allocation to Iran's energy sector. Energy. 2017;121:388-402.

[80] Christoforou A, Andreou AS. A framework for static and dynamic analysis of multi-layer fuzzy cognitive maps. Neurocomputing. 2017;232:133-45.

[81] Nikas A, Stavrakas V, Arsenopoulos A, Doukas H, Antosiewicz M, Witajewski-Baltvilks J, et al. Barriers to and consequences of a solar-based energy transition in Greece. Environmental Innovation and Societal Transitions. 2018.

[82] Mallampalli VR, Mavrommati G, Thompson J, Duveneck M, Meyer S, Ligmann-Zielinska A, et al. Methods for translating narrative scenarios into quantitative assessments of land use change. Environmental Modelling \& Software. 2016;82:7-20. 
